Article

\title{
A Synthetic Quantitative Precipitation Estimation by Integrating S- and C-Band Dual-Polarization Radars over Northern Taiwan
}

\author{
Ju-Yu Chen ${ }^{1}$, Wei-Yu Chang ${ }^{2, *}$ and Pao-Liang Chang ${ }^{3}$ \\ Institute for Geosciences, Section Meteorology, University of Bonn, 53121 Bonn, Germany; jchen@uni-bonn.de \\ 2 Department of Atmospheric Sciences, National Central University, Taoyuan 32001, Taiwan \\ 3 Central Weather Bureau, Taipei 100006, Taiwan; larkdi@cwb.gov.tw \\ * Correspondence: wychang@g.ncu.edu.tw
}

check for

updates

Citation: Chen, J.-Y.; Chang, W.-Y.; Chang, P.-L. A Synthetic Quantitative Precipitation Estimation by Integrating S- and C-Band Dual-Polarization Radars over Northern Taiwan. Remote Sens. 2021, 13, 154. https://doi.org/10.3390/ rs13010154

Received: 9 November 2020 Accepted: 31 December 2020 Published: 5 January 2021

Publisher's Note: MDPI stays neutral with regard to jurisdictional clai$\mathrm{ms}$ in published maps and institutional affiliations.

Copyright: (C) 2021 by the authors. Licensee MDPI, Basel, Switzerland. This article is an open access article distributed under the terms and conditions of the Creative Commons Attribution (CC BY) license (https:// creativecommons.org/licenses/by/ $4.0 /)$.

\begin{abstract}
The key factors, namely, the radar data quality, raindrop size distribution (RSD) variability, and the data integration method, which significantly affect radar-based quantitative precipitation estimation (QPE) are investigated using the RCWF (S-band) and NCU C-POL (C-band) dual-polarization radars in northern Taiwan. The radar data quality control (QC) procedures, including the corrections of attenuation, the systematic bias, and the wet-radome effect, have large impact on the QPE accuracy. With the proper QC procedures, the values of normalized root mean square error (NRMSE) decrease about $10 \sim 40 \%$ for $\mathrm{R}\left(\mathrm{Z}_{\mathrm{HH}}\right)$ and about $5 \sim 15 \%$ for $\mathrm{R}\left(\mathrm{K}_{\mathrm{DP}}\right)$. The QPE error from the RSD variability is mitigated by applying seasonal coefficients derived from eight-year disdrometer data. Instead of using discrete QPEs (D-QPE) from one radar, the synthetic QPEs are derived via discretely combined QPEs (DC-QPE) from S- and C-band radars. The improvements in DC-QPE compared to D-QPE are about $1.5-7.0 \%$ and $3.5-8.5 \%$ in $\mathrm{R}\left(\mathrm{K}_{\mathrm{DP}}\right)$ and $\mathrm{R}\left(\mathrm{K}_{\mathrm{DP}}, \mathrm{Z}_{\mathrm{DR}}\right)$, respectively. A novel algorithm, Lagrangian-evolution adjustment (LEA), is proposed to compensate D-QPE from a single radar. The LEA-QPE shows 1-4\% improvements in $\mathrm{R}\left(\mathrm{K}_{\mathrm{DP}}, \mathrm{Z}_{\mathrm{DR}}\right)$ at the $\mathrm{C}$-band radar, which has a larger scanning temporal gap (up to $10 \mathrm{~min}$ ). The synthetic LEA-QPEs by combining two radars have outperformed both D-QPEs and DC-QPEs.
\end{abstract}

Keywords: quantitative precipitation estimation; dual-polarization radar; Lagrangian evolution adjustment

\section{Introduction}

Accurate radar-based quantitative precipitation estimation (QPE) has been one of the longstanding goals of meteorological radar. Marshall and Palmer [1] utilized horizontal reflectivity $\left(Z_{\mathrm{HH}}, \mathrm{mm}^{6} \mathrm{~m}^{-3}\right)$ and a power-law relation, $\mathrm{Z}_{\mathrm{HH}}=\mathrm{aR}^{\mathrm{b}}(\mathrm{Z}-\mathrm{R})$ obtained from simulated radar variables based on measured raindrop size distribution (RSD), to estimate rainfall rate $\left(\mathrm{R}, \mathrm{mm} \mathrm{h}^{-1}\right)$. However, the $\mathrm{Z}-\mathrm{R}$ relation varies vastly in convective, stratiform precipitation, and different climatological regions due to the natural variability in RSD [2]. Seliga and Bringi [3] proposed dual-polarization (dual-pol) radar, which is capable of transmitting horizontal and vertical electromagnetic signals. Additional dual-pol variables from a dual-pol radar, such as the differential reflectivity $\left(Z_{D R}\right)$ and specific differential phase $\left(\mathrm{K}_{\mathrm{DP}}\right)$, are utilized in QPE. Consequently, the QPE has significantly been improved by the better quality of radar data and the inclusion of the RSD information [4-24].

Diverse forms of power-law QPE relations were recommended using single to multiple dual-pol radar parameters $\left(\mathrm{R}\left(\mathrm{Z}_{\mathrm{HH}}, \mathrm{Z}_{\mathrm{DR}}\right), \mathrm{R}\left(\mathrm{K}_{\mathrm{DP}}\right), \mathrm{R}\left(\mathrm{K}_{\mathrm{DP}}, \mathrm{Z}_{\mathrm{DR}}\right), \mathrm{R}\left(\mathrm{Z}_{\mathrm{HH}}, \mathrm{K}_{\mathrm{DP}}\right)\right.$, and $\left.\mathrm{R}\left(\mathrm{Z}_{\mathrm{HH}}, \mathrm{K}_{\mathrm{DP}}, \mathrm{Z}_{\mathrm{DR}}\right)\right)$; $[6-8,11,12,25]$. These QPE algorithms have shown pronounced improvements compared to the Z-R relation. More sophisticated QPE algorithms were explored to overcome various QPE issues. For instance, the variational-based algorithm is developed for attenuation correction and QPE simultaneously $[13,19,26]$. Moreover, the al- 
gorithm utilizing specific attenuation (i.e., R-A) has demonstrated its superiority in QPE as well [20-24].

Nevertheless, the dual-pol radar measurement uncertainties contribute to QPE error significantly $[11,27]$. The partial beam blockage (PBB), inadequate correction for attenuation, calibration of $Z_{\mathrm{HH}}$ and $\mathrm{Z}_{\mathrm{DR}}$, and the wet radome effect (WRE) are crucial to QPE application $[11,18,19,27-30]$. Furthermore, the variability of RSD also degrades the QPE performance even though dual-pol radar variables are applied. The QPE can be improved by using appropriate coefficients in the power-law relationships derived from local RSD measurements $[8,27]$. The RSD characteristics of Taiwan in the subtropical region are diverse among various precipitation systems. Chang et al. [31] has investigated the unique RSD of typhoon systems using a 2D-Video disdrometer. Lee et al. [32] further utilized a ten-year JWD disdrometer dataset to study the seasonal variability of RSD in northern Taiwan. The mean values of mass-weighted diameter $\left(D_{m}\right)$ vary from $1.5 \mathrm{~mm}$ of summer to $0.97 \mathrm{~mm}$ of winter, and the standard deviations of $\mathrm{D}_{\mathrm{m}}$ are about $0.34-0.49 \mathrm{~mm}$. It is essential to investigate the impacts of radar data quality control (QC) procedures (e.g., attenuation effect, the WRE) and unique RSD on Taiwan's QPE.

Taiwan's radar network consists of three Doppler single-pol S-band radars, one dualpol S-band radar, and eight dual-pol C-band radars [29]. These radars have two primary purposes: weather surveillance and QPE; thus, different scanning strategies with various spatiotemporal resolutions are applied accordingly [33]. Regarding the QPE, each radar has an individual scheme for operational QPE [29]. The mosaicked rainfall rate field of the whole Taiwan domain is generated from instantaneous QPE from each radar via the distance and height-weighted mean scheme. In order to further improve the accuracy of QPE from multiple radars, optimization of the QC procedures and QPE coefficients based on the radar frequencies and Taiwan RSD characteristics is needed.

Furthermore, synchronizing the QPE products from a network of multiple radars with different temporal resolutions and scanning sequences is very challenging in practice. The precipitation systems evolving vastly over one radar scan period may degrade the accuracy of accumulated rainfall estimation. Instead of deriving the accumulated rainfall by discretely integrating the individual QPE of each radar scan, a new integration method considering the movement and evolution of the precipitation system is required. The study from Ventura et al. [15] utilized the advection correction to reduce the error from low temporal resolution. Chen and Chandrasekar [17] used a Piecewise Cubic Hermite Interpolating Polynomial (PCHIP)-based interpolation methodology. Nevertheless, neither the advection correction nor the PCHIP method considers the evolution of precipitation systems.

This study aims to investigate the impact of critical factors on dual-pol QPE utilizing S- and C-band radars in northern Taiwan. The essential factors discussed here include the data QC procedures, RSD variability, and the QPE integration method. The final goal is to obtain the optimal composite rainfall estimation concurrently using two (or more in the future) different radars. Section 2 shows the radar data and related QC procedures. The RSD data, power-law QPE algorithms, and QPE integration method will be introduced in Section 3. The results of various QPEs will be examined in Section 4. Section 5 provides a brief summary, and Section 6 closes with a conclusion.

\section{Quality Control Procedures for S- and C-Band Dual-Polarization Radars}

RCWF (radar code of Wu-Fanshan, NEXRAD WSR-88D S-band dual-pol radar, Ryzhkov et al. [9] from the Central Weather Bureau (CWB) and NCU C-POL (National Central University C-band polarimetric radar) located in northern Taiwan are exploited in this study. Their basic information and locations are shown in Table 1 and Figure 1 , respectively. RCWF was upgraded to dual-pol radar around March of 2014 and remained operating until the Soudelor typhoon damaged the radome on 8 August in 2015. NCU C-POL is a research radar upgraded from a decommission Ericsson Doppler radar and has been utilized to study the RSD characteristics of typhoon systems associated with Taiwan's 
complex topography [31]. Both radars have the same signal processor (Sigmat RVP8), yet they have different configurations. As shown in Figure 1, these two radars have broad overlapping coverage in northern Taiwan. In addition, different frequencies are ideal to evaluate the performance of dual-pol QPE at different wavelengths.

Table 1. The basic information for RCWF (radar code of Wu-Fanshan, NEXRAD WSR-88D S-band dual-pol radar, Ryzhkov et al. [9] from the Central Weather Bureau (CWB) and NCU C-POL) National Central University C-band polarimetric radar).

\begin{tabular}{ccc}
\hline & RCWF & NCU C-POL \\
\hline Wavelength $(\mathrm{cm})$ & 10.7 & 5.3 \\
\hline Location (degree) & $121.77 \mathrm{~N}$ & $212.18 \mathrm{~N}$ \\
& $25.07 \mathrm{E}$ & $24.97 \mathrm{E}$ \\
\hline Height $(\mathrm{m})$ & 766 & 156 \\
\hline Range resolution $(\mathrm{m})$ & 250 & 250 \\
\hline Beam resolution (degree) & 0.5 & 1 \\
\hline
\end{tabular}

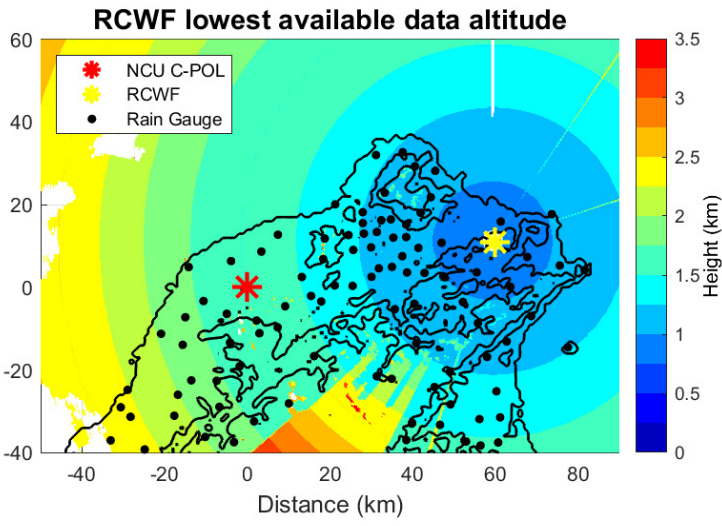

(a)

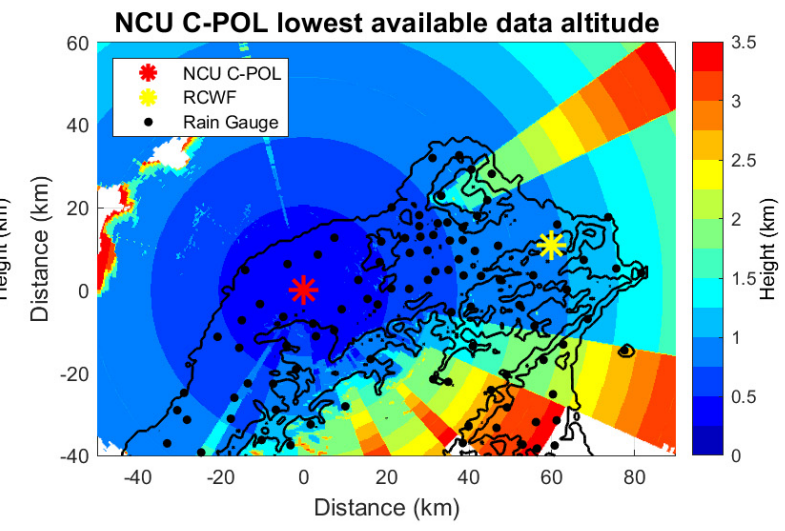

(b)

Figure 1. An example of (a) RCWF and (b) NCU C-POL lowest available data altitude $(\mathrm{km})$ for quantitative precipitation estimation (QPE) after the partial beam blockage (PBB) and non-meteorological signal removal.

Both RCWF and NCU C-POL have various data quality issues. Different distributions of PBB depending on the radar locations are displayed in Figure 1. Distinct ground clutter suppression configurations from different manufacturers induce distinct ground clutter characteristics. The degree of the attenuation effect varies according to radar wavelengths. Each radar has distinct characteristics of systematic $Z_{\mathrm{HH}}$ and $\mathrm{Z}_{\mathrm{DR}}$ biases due to different maintenance and calibration procedures (e.g., transmitter and receiver). Finally, different radome materials and radar frequencies cause distinct WREs. The QC procedures for both radars shown in Figure 2 (left panel) have been applied before the QPE retrievals. These procedures include the PBB and non-meteorological signal removal, the corrections of attenuation, the systematic bias, and the WRE. 


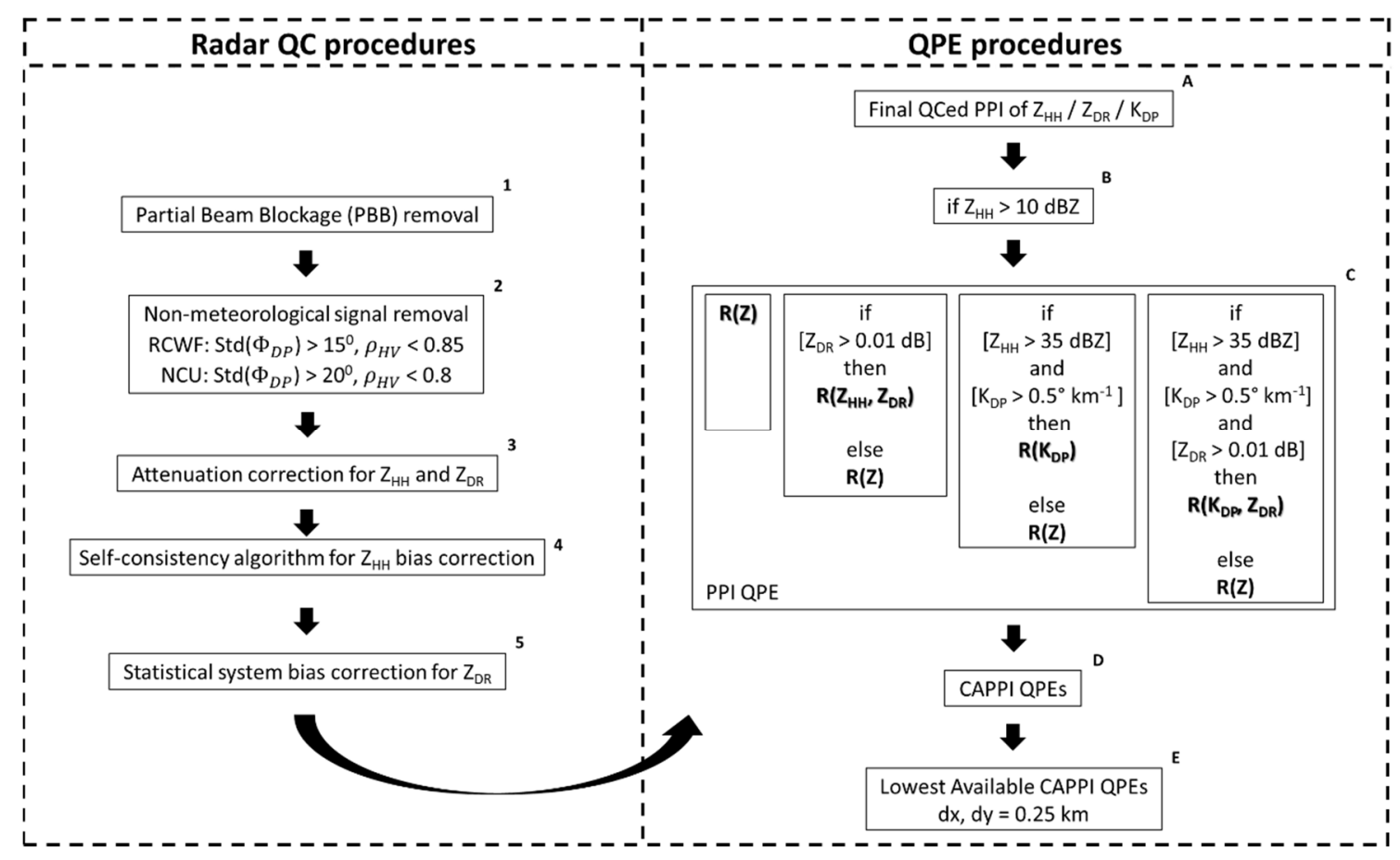

Figure 2. The flow chart of the quality control (QC) and QPE procedures.

\subsection{PBB Removal}

Radar data with the PBB effect, mainly resulting from Taiwan's complex topography, are first identified by a beam blockage simulation $[10,18,34,35]$. When the central height of the radar beams, estimated by $4 / 3$ of the Earth's radius model, is lower than the top of the terrain (50\% of the power is blocked), the data and the following bins along the radial will be removed.

\subsection{Non-Meteorological Signal Removal}

Despite the Doppler spectrum clutter suppression has been applied to both RCWF and NCU C-POL radars, some residual non-meteorological signals remain after the PBB removal. The standard deviation values of the differential propagation phase shift $\phi_{D P}$ of five radar bins along a radial (Std. $\phi_{D P}$ ) and the correlation coefficient $(C C)$ are subsequently used to filter out non-meteorological signals. The data with the values of Std. $\phi_{D P}$ higher than $15^{\circ}$ or with CC less than 0.85 is removed for RCWF. The corresponding threshold values of Std. $\phi_{D P}$ and CC for NCU C-POL are $20^{\circ}$ and 0.8 .

The threshold values of Std. $\phi_{D P}$ and CC for RCWF and NCU C-POL were obtained accordingly by examining large amounts of radar data. The values which preserve the most meteorological signal and reduce the most persistent ground clutters were selected as the threshold. The same technique has been applied to the operational Doppler dual-pol radars in Taiwan [33].

\subsection{Attenuation Correction}

The intrinsic $Z_{\mathrm{HH}}\left(Z_{\mathrm{HH}}^{\text {intrinsic }}\right)$ and $Z_{\mathrm{DR}}\left(Z_{\mathrm{DR}}^{\text {intrinsic }}\right)$ can be obtained after attenuation and bias corrections from the observational $Z_{\mathrm{HH}}\left(\mathrm{Z}_{\mathrm{HH}}^{\text {obs. }}\right)$ and $\mathrm{Z}_{\mathrm{DR}}\left(\mathrm{Z}_{\mathrm{DR}}^{\mathrm{obs}}\right)$ as bellow,

$$
\begin{gathered}
\mathrm{Z}_{\mathrm{HH}}^{\text {intrinsic }}=\mathrm{Z}_{\mathrm{HH}}^{\text {obs. }}+\mathrm{A}_{\mathrm{H}}+\mathrm{Z}_{\mathrm{HH}}^{\text {bias }} \text { and } \\
\mathrm{Z}_{\mathrm{DR}}^{\text {intrinsic }}=\mathrm{Z}_{\mathrm{DR}}^{\text {obs. }}+\mathrm{A}_{\mathrm{HV}}+\mathrm{Z}_{\mathrm{DR}}^{\text {bias }} .
\end{gathered}
$$


The attenuation effects of $\mathrm{Z}_{\mathrm{HH}}$ and $\mathrm{Z}_{\mathrm{DR}}$ on both RCWF and NCU C-POL are corrected by the $\phi_{D P}$-based algorithm. The horizontal attenuation $\left(\mathrm{A}_{\mathrm{H}}, \mathrm{dB}\right)$ and differential attenuation $\left(\mathrm{A}_{\mathrm{HV}}, \mathrm{dB}\right)$ can be estimated as follows,

$$
\begin{gathered}
\mathrm{A}_{\mathrm{H}}=\alpha \Delta \phi_{D P} \text { and } \\
\mathrm{A}_{\mathrm{HV}}=\beta \Delta \phi_{D P} .
\end{gathered}
$$

The coefficients of $\alpha$ and $\beta$ for S-band (C-band) radar are $0.0151 \mathrm{~dB} \mathrm{deg}^{-1}$ $\left(0.0727 \mathrm{~dB} \mathrm{deg}^{-1}\right)$ and $0.0025 \mathrm{~dB} \mathrm{deg}^{-1}\left(0.0161 \mathrm{~dB} \mathrm{deg}^{-1}\right)$, respectively. These coefficients were obtained from the long-term RSD measurements in northern Taiwan. The RSD data and implementation of coefficient calculations will be discussed in Sections 3.1 and 3.2, respectively.

\section{4. $Z_{H H}$ Systematic Bias and the WRE Correction}

The next step is to correct $\mathrm{Z}_{\mathrm{HH}}$ biases including the radar systematic bias (i.e., the miscalibration of transmitter and receiver) and the WRE. The self-consistency among the $\mathrm{Z}_{\mathrm{HH}}, \mathrm{Z}_{\mathrm{DR}}$, and $\mathrm{K}_{\mathrm{DP}}$ measurements of rain has been utilized to estimate the radar systematic bias [36]. The WRE is an additional bias due to the attenuation effect of the water coated over the radome while a precipitation system is located over the radar site. It has similar characteristics to the radar systematic bias. Therefore, the $\mathrm{Z}_{\mathrm{HH}}$ biases which consist of both radar systematic bias and WRE can be calculated via the self-consistency method. The radar systematic bias is obtained by averaging the $\mathrm{Z}_{\mathrm{HH}}$ biases of no-WRE events (identified by the rain gauge measurements next to the radar site). Hence, the attenuation of $Z_{\mathrm{HH}}$ from the WRE can be derived by examining the excess of estimated $Z_{\mathrm{HH}}$ biases from the systematic bias. On the other hand, the WRE of $Z_{\mathrm{DR}}$ measurements depends on the forms in which the rain accumulates on the radome [37-41]. The forms could be droplets, rivulets, or non-uniform film and cause diverse WREs of $Z_{D R}$. It is difficult to estimate the WRE of $Z_{D R}$, and there is no practical technique either. Consequently, $Z_{D R}$ is also excluded from the self-consistency algorithm for the $Z_{\mathrm{HH}}$ bias estimation [36] to avoid WRE-contaminated $\mathrm{Z}_{\mathrm{DR}}$.

Here, the attenuation-corrected $\mathrm{Z}_{\mathrm{HH}}\left(\mathrm{Z}_{\mathrm{HH}}^{\text {corr. }}\right.$, in $\left.\mathrm{mm}^{6} \mathrm{~m}^{-3}\right)$ data of rain is applied to the $\mathrm{K}_{\mathrm{DP}}-\mathrm{Z}_{\mathrm{HH}}$ relation to obtain the value of $K_{D P}^{\prime}$ in each radar bin as shown below,

$$
K_{D P}^{\prime}=a \mathrm{Z}_{\mathrm{HH}}^{\text {corr.b }} .
$$

Based on the RSD measurements in Section 3.2, the coefficients a and $\mathrm{b}$ are $5.3 \times 10^{-5}$ $\left(2.5 \times 10^{-4}\right)$ and $0.88(0.81)$ for S-band (C-band) radar. The calculated $K_{D P}^{\prime}$ of each radar bin is then integrated along a radial to derive the increments of differential phase shift $\left(\triangle \Phi_{D P}^{\prime}\right)$ as

$$
\Delta \Phi_{D P}^{\prime}=2 \int K_{D P}^{\prime} d r=2 \int a \mathrm{Z}_{\mathrm{HH}}^{\text {corr.b }} d r
$$

$\mathrm{dr}$ is the radial resolution of radar data [36]. Since the phase measurement (i.e., $\Delta \Phi_{D P}$ ) is not affected by the absolute calibration of the radar system and attenuation [11,36], the $\mathrm{Z}_{\mathrm{HH}}$ bias $\left(\mathrm{Z}_{\mathrm{HH}}^{\text {bias }}\right)$ including both the radar systematic and the WRE biases can be estimated via the calculated $\Delta \Phi_{D P}^{\prime}$ and the measured $\Delta \Phi_{D P}$ as

$$
\mathrm{Z}_{\mathrm{HH}}^{\mathrm{bias}}=\frac{1}{\mathrm{~b}} \log _{10}\left(\frac{\Delta \Phi_{D P}^{\prime}}{\Delta \Phi_{D P}}\right) .
$$

In practice, the last valid $\Delta \Phi_{D P}^{\prime}$ and $\Delta \Phi_{D P}$ data along a radial below the freezing level (avoid non-liquid phase data) are used to calculate radial-wise $Z_{\mathrm{HH}}^{\text {bias }}$. The values of $\Delta \Phi_{D P}^{\prime}$ is higher than $\Delta \Phi_{D P}$ when $Z_{H H}$ is over-calibrated (i.e., positive $Z_{H H}$ bias), and vice versa. Then the scan-wise representative $Z_{\mathrm{HH}}$ bias is determined via the mean value of radial-wise 
$\mathrm{Z}_{\mathrm{HH}}^{\text {bias }}$ within one scan for the bias correction. Only the WRE of $\mathrm{Z}_{\mathrm{HH}}$ was considered via a self-consistency technique. The WRE of $Z_{D R}$ was not corrected in this study.

\section{5. $Z_{D R}$ Systematic Bias Correction}

The last remaining radar measurement error in the QC processes is $Z_{D R}$ systematic bias. Since both radars cannot perform vertical pointing scan (birdbath scan), the $Z_{\mathrm{DR}}$ systematic bias is estimated by statistical analysis. The stratiform rain consisting of small sizes of raindrops mostly has $Z_{D R}$ values slightly above $0 \mathrm{~dB}$. This $Z_{\mathrm{DR}}$ characteristic of light rain is used for $Z_{D R}$ bias estimation. The mean $Z_{D R}$ averaged from the RSD-simulated $Z_{\mathrm{DR}}$ of light rain (i.e., $0.19 \mathrm{~dB}$ ), mainly the data with $Z_{\mathrm{HH}}$ values from 10 to $20 \mathrm{dBZ}$, is considered as a reference. The difference between the mean value of radar-measured $Z_{D R}$ in the light rain region and the reference value is thus reasonably viewed as $Z_{D R}$ systematic bias. For example, the mean $Z_{\mathrm{DR}}$ value in the light rain region from NCU C-POL was $-0.28 \mathrm{~dB}$, then the $\mathrm{Z}_{\mathrm{DR}}$ bias was determined as $-0.47 \mathrm{~dB}$. The $\mathrm{Z}_{\mathrm{DR}}$ biases of NCU C-POL were derived case by case and the values were within the range of -0.21 to $-0.48 \mathrm{~dB}$ in this study. RCWF is a well-calibrated radar; therefore, $\mathrm{Z}_{\mathrm{DR}}$ calibration was not applied.

\section{Quantitative Precipitation Estimation from S- and C-Band Dual-Polarization Radars}

The RSD data obtained from the disdrometer was used to derive the coefficients for the aforementioned QC procedures and dual-pol QPE algorithms. The procedures of processing RSD data, deriving the coefficients of QPE relations, and developing different QPE (decision-tree) products are introduced. In addition, two integration methods intending to improve QPE performance are also described in this section.

\subsection{Disdrometer Data}

In this research, the RSD data collected by a 2D-Video Disdrometer (2DVD, [42]) located at NCU from October of 2000 to June of 2007 is used to characterize the RSD in northern Taiwan. The 2DVD records the particle diameter (D) and the terminal velocity $\left(\mathrm{V}_{\mathrm{t}}\right)$ of each raindrop. The data is quality controlled by the $V_{t}$-based filter technique $[31,43,44]$. The 6-min RSD is then calculated to ensure sufficient raindrop sampling numbers of each RSD [19,31,32,45]. Moreover, the rainfall rates of less than $1 \mathrm{~mm} \mathrm{~h}^{-1}$ are removed to eliminate inadequate RSD data set. There are a total of 14,314 quality-controlled minutely RSDs available for analysis.

Chen and Chen [46] has investigated the characteristics of Taiwan's precipitation systems and classified them into five distinct types. They are spring rain from March to April, Mei-Yu from May to June, summer convection from July to September, winter cold front from October to February, and typhoon systems. Most of the systems can be approximated simply by month, except typhoon is case-selected. Lee et al. [32] utilized the same classification and demonstrated unique RSD characteristics of these five types of precipitation systems. The bigger mean raindrop size (i.e., mass-weighted diameter) from $\mathrm{Mei}-\mathrm{Yu}$, summer convection, and typhoon events is found compared to spring rain and winter cold front.

The NCU 2DVD data is thus classified according to Chen and Chen [46]. The rainfall intensities of 6-min RSD for each precipitation type are summarized in Figure 3. The majority of rainfall intensities are less than $15 \mathrm{~mm} \mathrm{~h}^{-1}$. The maximum rainfall rates of all types of precipitation are around or above $70 \mathrm{~mm} \mathrm{~h}^{-1}$. The Mei-Yu and typhoon season have similar maximum rainfall up to $90 \mathrm{~mm} \mathrm{~h}^{-1}$. The rainfall rates of the cold front are mostly below $5 \mathrm{~mm} \mathrm{~h}^{-1}$. These quality-controlled and classified RSD data are consequently used to derive the coefficients of various QPE relations. 


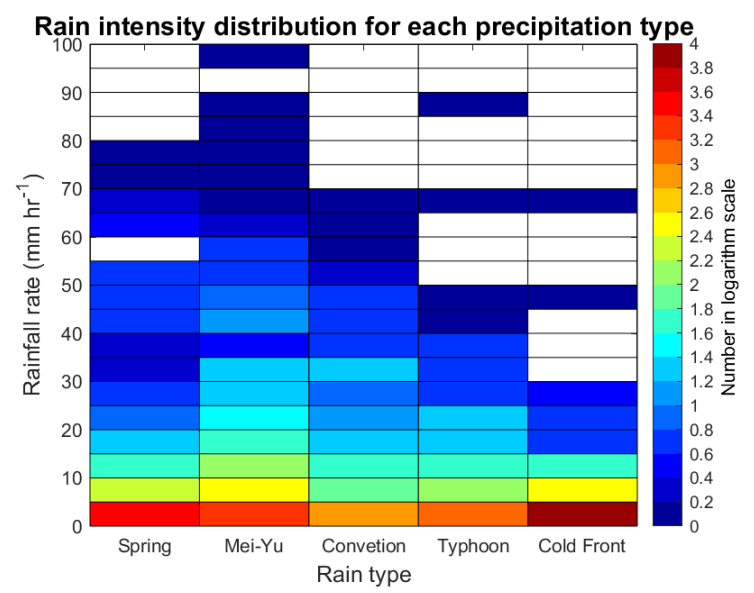

Figure 3. The distribution of rainfall intensities calculated from 6-min raindrop size distributions (RSDs) for different precipitation types (spring rain, Mei-Yu, convection, typhoon, and cold front).

\subsection{QPE Coefficients}

Various forms of power-law relationship using one to two dual-pol parameters were proposed to improve QPE, namely $\mathrm{R}\left(\mathrm{K}_{\mathrm{DP}}\right)[6,11,25], \mathrm{R}\left(\mathrm{Z}_{\mathrm{HH}}, \mathrm{Z}_{\mathrm{DR}}\right)$ [8,12], and $\mathrm{R}\left(\mathrm{K}_{\mathrm{DP}}\right.$, $\left.Z_{\mathrm{DR}}\right)[7,8]$. The conventional $\mathrm{Z}-\mathrm{R}$ and the most common dual-pol relations used in this study are shown in the following,

$$
\begin{gathered}
\mathrm{R}\left(\mathrm{Z}_{\mathrm{HH}}\right)=a_{1} \mathrm{Z}_{\mathrm{HH}^{\prime}}^{\mathrm{b}_{1}} \\
\mathrm{R}\left(\mathrm{Z}_{\mathrm{HH}}, \mathrm{Z}_{\mathrm{DR}}\right)=a_{2} \mathrm{Z}_{\mathrm{HH}}^{\mathrm{b}_{2}} \mathrm{Z}_{\mathrm{DR}^{\prime}}^{\mathrm{c}_{2}} \\
\mathrm{R}\left(\mathrm{K}_{\mathrm{DP}}\right)=a_{3} \mathrm{~K}_{\mathrm{DP}}^{\mathrm{b}_{3}} \text { and } \\
\mathrm{R}\left(\mathrm{K}_{\mathrm{DP}}, \mathrm{Z}_{\mathrm{DR}}\right)=a_{4} \mathrm{~K}_{\mathrm{DP}}^{\mathrm{b}_{4}} \mathrm{Z}_{\mathrm{DR}}^{\mathrm{c}_{4}} .
\end{gathered}
$$

Lee [27] has shown that the RSD variability is one of the significant error sources in radar-based QPE. Thus, the correspondingly precipitation-type coefficients in dual-pol QPE relations are derived for reducing QPE error from the seasonal RSD variabilities [32]. First, the $\mathrm{S}$ - and $\mathrm{C}$-band radar variables (i.e., $\mathrm{Z}_{\mathrm{HH}}, \mathrm{Z}_{\mathrm{DR}}, \mathrm{K}_{\mathrm{DP}}, \mathrm{A}_{\mathrm{H}}, \mathrm{A}_{\mathrm{HV}}$ ) are computed through the T-matrix scattering calculation [47] using the measured 6-min RSDs data set from NCU 2DVD, with the assumption of raindrop axis-ratio proposed by Brandes et al. [48] and Chang et al. [31] to non-typhoon cases and typhoon cases, respectively. Then the coefficients of Equations (8)-(11) for five types of precipitations (hereafter, seasonal coefficients) are derived by fitting the simulated radar variables and RSD-derived rainfall rates via the Levenberg-Marquardt algorithm [49] at both frequencies. Diverse coefficients due to the natural RSD variability among precipitation systems can be noticed. The coefficients based on the entire database (hereafter, all-season coefficients) are also obtained for comparison (Tables 2 and 3). The same procedures is also utilized to derive the coefficients of the attenuation correction and self-consistency relationship in Equations (3)-(5). 
Table 2. The coefficients of four power-law rain rate relations for S-band radar. The all-season coefficients are derived from the entire database measured by a 2D-Video Disdrometer (2DVD) at National Central University (NCU). The seasonal coefficients are classified into spring, Mei-Yu, summer convection, typhoon, and winter cold front.

\begin{tabular}{|c|c|c|c|c|c|c|c|}
\hline & & All-Season & Spring & Mei-Yu & Summer Convection & Typhoon & Winter Cold Front \\
\hline \multirow{2}{*}{$\mathrm{R}\left(\mathrm{Z}_{\mathrm{HH}}\right)$} & a1 & 0.0279 & 0.0197 & 0.0244 & 0.0435 & 0.0282 & 0.0408 \\
\hline & b1 & 0.6619 & 0.6874 & 0.6779 & 0.6233 & 0.6624 & 0.6173 \\
\hline \multirow{3}{*}{$\mathrm{R}\left(\mathrm{Z}_{\mathrm{HH}}, \mathrm{Z}_{\mathrm{DR}}\right)$} & a2 & 0.0046 & 0.0019 & 0.0018 & 0.0011 & 0.0013 & 0.0033 \\
\hline & $\mathrm{b} 2$ & 0.8492 & 0.9452 & 0.9578 & 1.0017 & 0.9490 & 0.8888 \\
\hline & $\mathrm{c} 2$ & -0.6193 & -0.9734 & -1.0434 & -1.1240 & -0.7988 & -0.7439 \\
\hline \multirow{2}{*}{$\mathrm{R}\left(\mathrm{K}_{\mathrm{DP}}\right)$} & a3 & 47.5998 & 44.6864 & 48.0516 & 48.3448 & 64.3293 & 42.5163 \\
\hline & b3 & 0.7605 & 0.7950 & 0.7915 & 0.7725 & 0.7278 & 0.7225 \\
\hline \multirow{3}{*}{$\mathrm{R}\left(\mathrm{K}_{\mathrm{DP}}, \mathrm{Z}_{\mathrm{DR}}\right)$} & $\mathrm{a} 4$ & 64.8411 & 61.9421 & 62.3633 & 63.3633 & 73.0964 & 60.2012 \\
\hline & $\mathrm{b} 4$ & 0.9880 & 0.9782 & 0.9727 & 0.9727 & 0.9476 & 0.9486 \\
\hline & $\mathrm{c} 4$ & -0.6921 & -0.6445 & -0.6196 & -0.6196 & -0.6039 & -0.5836 \\
\hline
\end{tabular}

Table 3. Same as Table 2 but for C-band radar.

\begin{tabular}{|c|c|c|c|c|c|c|c|}
\hline & & All-Season & Spring & Mei-Yu & Summer Convection & Typhoon & Winter Cold Front \\
\hline \multirow{2}{*}{$\mathrm{R}\left(\mathrm{Z}_{\mathrm{HH}}\right)$} & a1 & 0.0376 & 0.0260 & 0.0316 & 0.0710 & 0.0360 & 0.0434 \\
\hline & b1 & 0.6340 & 0.6330 & 0.6558 & 0.5761 & 0.6394 & 0.6138 \\
\hline \multirow{3}{*}{$\mathrm{R}\left(\mathrm{Z}_{\mathrm{HH}}, \mathrm{Z}_{\mathrm{DR}}\right)$} & $\mathrm{a} 2$ & 0.0035 & 0.0014 & 0.0014 & 0.0013 & 0.0010 & 0.0028 \\
\hline & $\mathrm{b} 2$ & 0.8886 & 0.9922 & 0.9952 & 1.0018 & 0.9812 & 0.9199 \\
\hline & $\mathrm{c} 2$ & -0.6575 & -0.9840 & -1.0031 & -1.0239 & -0.7714 & -0.7474 \\
\hline \multirow{2}{*}{$\mathrm{R}\left(\mathrm{K}_{\mathrm{DP}}\right)$} & a3 & 26.2343 & 23.9480 & 25.8619 & 26.4884 & 36.1670 & 24.0925 \\
\hline & b3 & 0.7485 & 0.7823 & 0.7784 & 0.7590 & 0.7158 & 0.7103 \\
\hline \multirow{3}{*}{$\mathrm{R}\left(\mathrm{K}_{\mathrm{DP}}, \mathrm{Z}_{\mathrm{DR}}\right)$} & $\mathrm{a} 4$ & 31.2514 & 29.8459 & 30.4106 & 29.9747 & 36.8965 & 30.3301 \\
\hline & $\mathrm{b} 4$ & 0.9648 & 0.9563 & 0.9593 & 0.9381 & 0.9212 & 0.9500 \\
\hline & $\mathrm{c} 4$ & -0.5988 & -0.5334 & -0.5418 & -0.5132 & -0.5146 & -0.5717 \\
\hline
\end{tabular}

The seasonal coefficients are expected to diminish the RSD variations by considering the seasonal RSD characteristics, thus outperform all-season coefficients. The benefit of optimized QPE coefficients is first examined via the simulated data. The estimated rainfall $\left(\mathrm{R}_{\mathrm{est}}\right)$ using seasonal and all-season coefficients, respectively, are derived from the RSDsimulated radar variables, and its performance is validated against RSD-derived rainfall rates $\left(R_{t}\right)$. Since radar variables and $R_{t}$ are both based on the same database, namely, without radar measurement errors, the influence of the RSD variability on QPE can be investigated solely. The normalized bias (NBIAS) and normalized root mean square error (NRMSE) are calculated for validation,

$$
\begin{aligned}
\text { NBIAS } & =\frac{\frac{\sum\left(\mathrm{R}_{\mathrm{t}}-\mathrm{R}_{\mathrm{est}}\right)}{\mathrm{N}}}{\overline{\mathrm{R}_{\mathrm{t}}}} \text { and } \\
\mathrm{NRMSE} & =\frac{\left(\frac{\sum\left(\mathrm{R}_{\mathrm{t}}-\mathrm{R}_{\mathrm{est}}\right)^{2}}{\mathrm{~N}}\right)^{0.5}}{\overline{\mathrm{R}_{\mathrm{t}}}} .
\end{aligned}
$$

$\mathrm{N}$ is the number of RSD. 
The results in Figure 4 (upper panel) show that the values of NBIAS of QPEs using seasonal coefficients are closer to 0 than using all-season coefficients at $S$ band, while $C$ band QPEs have comparable results. The NRMSEs of QPEs using seasonal coefficients are consistently lower than using all-season coefficients (Figure 4 lower panel). The improvements from applying seasonal coefficients are most pronounced in $\mathrm{R}\left(\mathrm{K}_{\mathrm{DP}}\right)$ and less evident in $\mathrm{R}\left(\mathrm{Z}_{\mathrm{HH}}\right)$. It can be explained by the fact that the seasonal variability of Taiwan RSD is mostly owing to small to medium sizes of raindrops [32] by which $\mathrm{K}_{\mathrm{DP}}$ is dominated. Moreover, the $\mathrm{K}_{\mathrm{DP}}$-based algorithms outperform $\mathrm{Z}_{\mathrm{HH}}$-based algorithms at both $\mathrm{C}$ and $\mathrm{S}$ bands. $\mathrm{R}\left(\mathrm{K}_{\mathrm{DP}}, \mathrm{Z}_{\mathrm{DR}}\right)$ has the lowest NRMSE due to the additional RSD information from $Z_{\text {DR }}$. The results show a good agreement with Bringi and Chandrasekar [11] and Lee [27]. Even though dual-pol radar variables have been utilized, applying seasonal coefficients in QPE relations further reduces the QPE uncertainty by diminishing the RSD variability.

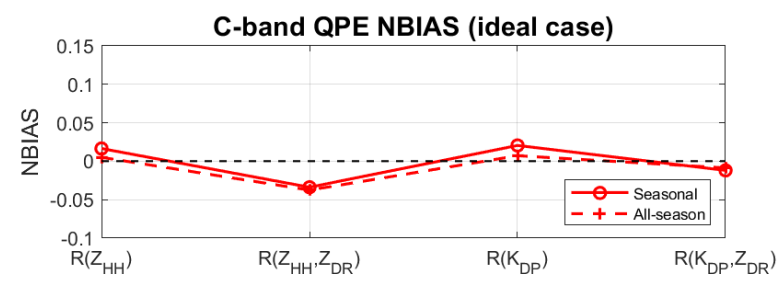

(a)

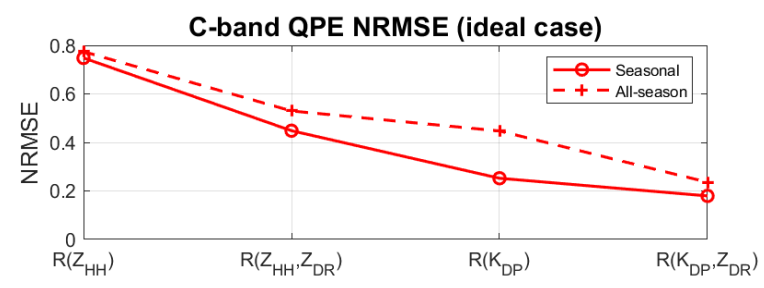

(c)

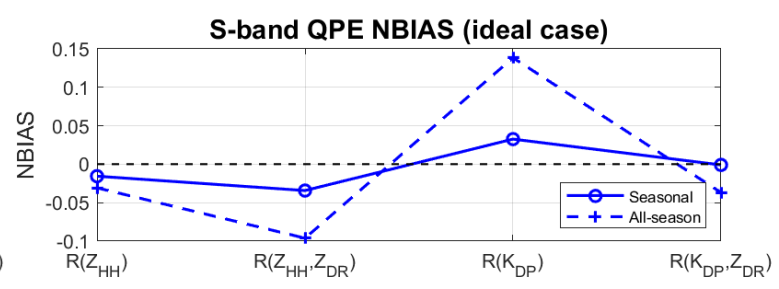

(b)

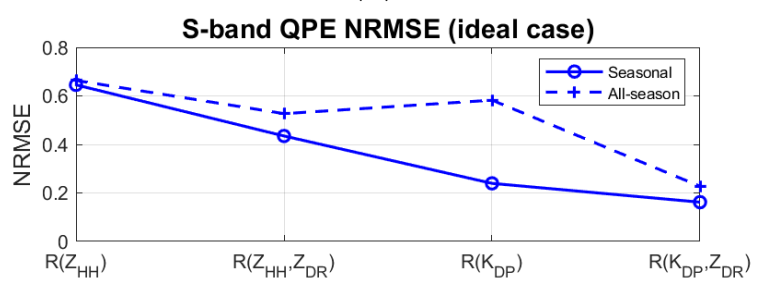

(d)

Figure 4. The normalized bias (NBIAS) of estimated rainfall rates using seasonal (solid lines) and all-season (dashed lines) coefficients at (a) C-band and (b) S-band. (c) and (d) are the same but for the normalized root mean square error (NRMSE). The estimated rainfall rates are derived from the RSD-simulated radar variables and compared to RSD-derived rainfall rates for the theoretical verification.

\subsection{Simplified Decision-Tree QPE}

In practice, various dual-pol radar measurement errors cause a decline in QPE performance [27]. For instance, the noisy $Z_{D R}$ due to a fast-scanning radar with a low sampling rate $[11,28]$ severely affects $Z_{D R}$-based QPEs. The range-derivative $K_{D P}$ estimated from $\phi_{D P}$ requires various filtering techniques $[8,11,50-53]$ and introduces more uncertainty in $\mathrm{K}_{\mathrm{DP}}$-based QPEs. In the case of light rain, $\mathrm{K}_{\mathrm{DP}}$ is too small to be estimated with sufficient accuracy. The combination of different dual-pol QPE algorithms using decision-tree logic was thus proposed $[8,9,14,16,54]$. The superiority of this composite method over a single dual-pol algorithm has been proved [8].

Most of the decision-tree algorithms use more than two dual-pol QPE relationships. For example, studies from [14,16,54] utilize three dual-pol QPE relationships including $R(Z), R\left(Z_{H H}, Z_{D R}\right)$, and $R\left(K_{D P}, Z_{D R}\right)$ for their final QPE products. In this study, however, each dual-pol QPE algorithm is combined with $\mathrm{R}(Z)$ only. The purpose of utilizing simplified decision-tree algorithms is to examine the performance of specific dual-pol QPE relationships solely. In Figure 2 (right panel), the decision-tree algorithms are applied to quality-controlled plan position indicator (PPI) radar data. An additional filter of $\mathrm{Z}_{\mathrm{HH}}$ less than $10 \mathrm{dBZ}$, whose contribution to accumulated rainfall is neglectable, is applied. Each algorithm has its own criteria to assign different QPE relationships (Step C). The criteria were determined theoretically based on the dual-pol radar principle [11] and empirically 
adopted from previous researches. The concept is to avoid using inaccurate $\mathrm{K}_{\mathrm{DP}}$ in light rain and negative-biased $Z_{D R}$ due to the WRE in pure rain. For clarity, the simplified decision-tree $\mathrm{QPE}$ combining $\mathrm{Z}-\mathrm{R}$ with $\mathrm{R}\left(\mathrm{Z}_{\mathrm{HH}}, \mathrm{Z}_{\mathrm{DR}}\right), \mathrm{R}\left(\mathrm{K}_{\mathrm{DP}}\right)$ or $\mathrm{R}\left(\mathrm{K}_{\mathrm{DP}}, \mathrm{Z}_{\mathrm{DR}}\right)$ are referred to $\mathrm{R}\left(\mathrm{Z}_{\mathrm{HH}}, \mathrm{Z}_{\mathrm{DR}}\right), \mathrm{R}\left(\mathrm{K}_{\mathrm{DP}}\right)$ or $\mathrm{R}\left(\mathrm{K}_{\mathrm{DP}}, \mathrm{Z}_{\mathrm{DR}}\right) \mathrm{QPEs}$, hereafter. To derive the composite QPE, the PPI QPE is then interpolated into the Cartesian coordinate. The lowest available Cartesian QPE is implemented as a final composite QPE product. These procedures are similar to Kwon et al. [18].

\subsection{Integration Methods for Radar-Based QPE}

Conventionally, the radar-based QPE is obtained by integrating each radar scan discretely, hereafter D-QPE ( $\Delta T_{i}$ : time difference between two scans). The D-QPE of rapidlyevolving severe precipitation systems suffers from an inadequate radar scanning rate. Some researches proposed different solutions, namely the advection correction [15] and PCHIP interpolation [17]. Nevertheless, the influence of the evolution of the precipitation systems on QPE has not been well investigated. As aforementioned the time resolutions of RCWF and NCU C-POL were not synchronized and varied between 5 to $10 \mathrm{~min}$ (Table 4). To overcome this issue, the D-QPEs from asynchronous radars are "discretely" combined (hereafter, DC-QPE) to increase temporal resolution. The DC-QPE then can better reveal the evolution of precipitation than D-QPE does. Figure 5 displays an example that the NCU C-POL (red circles) and RCWF (blue crosses) D-QPEs are "discretely" combined whenever it is available (marked by black triangles). Hence, the DC-QPE has more sampling numbers.

Table 4. The information of 18 heavy rainfall events investigated in this study.

\begin{tabular}{|c|c|c|c|c|}
\hline \multirow{2}{*}{ Date (hour) } & \multirow{2}{*}{ Precipitation Type } & \multirow{2}{*}{$\begin{array}{c}\text { Max. Hourly Rainfall } \\
\left(\mathrm{mm} \mathrm{h}^{-1}\right) / \text { Accumulated Rainfall }(\mathrm{mm})\end{array}$} & \multicolumn{2}{|c|}{ Scan Time (min:s) } \\
\hline & & & RCWF & NCU C-POL \\
\hline 26 April 2014 (1 h) & Spring & 60 & $5: 50$ & $6: 40$ \\
\hline 5 May 2014 (2 h) & Mei-Yu & $20 / 33$ & $5: 50$ & $6: 40$ \\
\hline 9 May 2014 (2 h) & Mei-Yu & $23.5 / 35$ & 5:50 & $6: 40$ \\
\hline 15 May 2014 (1 h) & Mei-Yu & 57.5 & $5: 50$ & $6: 40$ \\
\hline 20 May 2014 (3 h) & Mei-Yu & $26 / 50$ & $5: 50$ & $6: 40$ \\
\hline 21 May 2014 (2 h) & Mei-Yu & $38 / 52.5$ & $5: 50$ & $6: 40$ \\
\hline 29 May $2014(6$ h) & Mei-Yu & $56.5 / 115$ & $5: 50$ & $6: 40$ \\
\hline 5 June 2014 (6 h) & Mei-Yu & $46 / 135.5$ & $5: 50$ & $6: 40$ \\
\hline 7 June 2014 (1 h) & Mei-Yu & 35 & $5: 50$ & $6: 40$ \\
\hline 31 July 2014 (1 h) & Summer convection & 48.5 & $5: 50$ & 10:00 \\
\hline 13 August 2014 (1 h) & Summer convection & 36.5 & $5: 50$ & $10: 00$ \\
\hline 19 August 2014 (3 h) & Summer convection & $71.5 / 92.5$ & $5: 50$ & 10:00 \\
\hline 24 February 2015 (4 h) & Cold front & $29.5 / 58.5$ & $5: 50$ & $10: 00$ \\
\hline 12 May 2015 (2 h) & Mei-Yu & $41.5 / 50.5$ & $5: 50$ & $10: 00$ \\
\hline 22 May 2015 (2 h) & Mei-Yu & $19.5 / 28$ & $5: 50$ & 10:00 \\
\hline 6 June 2015 (2 h) & Mei-Yu & $37 / 45.5$ & $5: 50$ & 10:00 \\
\hline 14 June 2015 (2 h) & Mei-Yu & $103.5 / 167$ & 5:50 & 10:00/12:30 \\
\hline 23 July 2015 (2 h) & Summer convection & $74 / 80$ & $5: 50$ & 10:00/12:30 \\
\hline
\end{tabular}




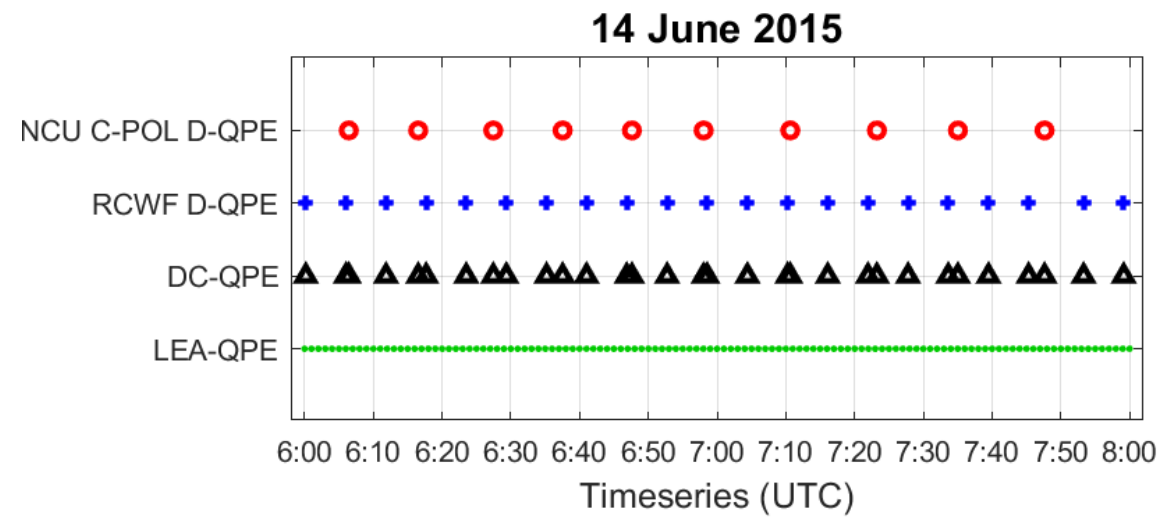

Figure 5. An example of time steps of available data for QPE on 14 June, 2015. Red circles represent the NCU C-POL discrete QPE (NCU C-POL D-QPE), and blue crosses for the RCWF discrete QPE (RCWF D-QPE). Black triangles are the discretely combined C- and S-band QPE (DC-QPE) and green dots are the Lagrangian-evolution adjustment QPE (LEA-QPE).

However, not every location can be covered by two radars or more. A novel algorithm, namely Lagrangian-evolution adjustment (LEA), is developed for improving D-QPE/DCQPE in this study. The QPEs from $R_{T_{i}}$ and $R_{T_{i+1}}$ are first used to derive the advection speed and direction of precipitation movement via tracking radar echo based on the crosscorrelation (TREC, [15,55]). Thus, the $R_{T_{i}}$ can be forward advected to $T_{i+1}\left(=T_{i}+\Delta T_{i}\right)$, and the $R_{T_{i+1}}$ can be backward advected to $T_{i}$. The evolution of the precipitation system between $T_{i}$ and $T_{i+1}$ is subsequently estimated via time-weighted linear interpolation. The linear interpolated QPE $\left(R_{T_{i}+\Delta t_{j}}\right)$ at $T_{i}+\Delta t_{j}$ is derived as follows,

$$
R_{T_{i}+\Delta t_{j}}=R_{T_{i}} \frac{\Delta T_{i}-\Delta t_{j}}{\Delta T_{i}}+R_{T_{i}+\Delta T_{i}} \frac{\Delta t_{j}}{\Delta T_{i}} .
$$

The interval of $\Delta t_{j}$ is defined as one minute (Figure 5 green dots) in this study. The seamless LEA-QPEs with the considerations of the advection and evolution of the precipitation systems are implemented between $T_{i}$ and $T_{i+1}$.

\section{QPE Comparison between C- and S-Band Radar}

Eighteen heavy rainfall events for real case studies were selected by examining the rain gauge measurements in northern Taiwan (Table 4). Most of the events are from the Mei-Yu season (East Asia rainy season, from mid-May to mid-June for Taiwan), since it contributes to most of the rainfall in Taiwan [46]. The most intensive hourly rainfall rate and highest event-accumulated rainfall are $103.5 \mathrm{~mm} \mathrm{~h}^{-1}$ and $167.0 \mathrm{~mm}$ on 14 June, 2015 . RCWF and NCU C-POL have diverse scanning strategies and configurations. RCWF has higher azimuthal and temporal resolution compared to NCU C-POL (Tables 1 and 4). The advantage of NCU C-POL is its location at a relatively lower altitude $(156 \mathrm{~m})$ than RCWF $(766 \mathrm{~m})$, providing closer observations to the surface and less vertical discrepancy than RCWF. QPE performances are evaluated against operational tipping bucket rain gauge measurements which are collected and maintained by CWB (black dots in Figure 1). For clarity, the S- and C-band QPEs will refer to RCWF and NCU C-POL QPEs hereafter.

\subsection{The Influence of QC Procedures on C- and S-Band QPE}

As discussed in previous studies [11], the $\mathrm{K}_{\mathrm{DP}}$-based QPEs are immune to the systematic bias or attenuation effect and are expected to have better performance than $Z_{\mathrm{HH}}$-based QPEs. Nevertheless, $Z_{\mathrm{HH}}$-based QPEs are still applied in the simplified decision-tree QPE algorithms for specific purposes (e.g., avoid noisy $\mathrm{K}_{\mathrm{DP}}$ in light rain). Thus, it is essential to examine the impacts of various measurement errors from attenuation and the WRE on QPE. 
To avoid WRE-contaminated $\mathrm{Z}_{\mathrm{DR}}$ error in the analysis, only $\mathrm{R}\left(\mathrm{Z}_{\mathrm{HH}}\right)$ and $\mathrm{R}\left(\mathrm{K}_{\mathrm{DP}}\right)$ are examined for comparison. As shown in Figure 6, both the C-band $R\left(Z_{H H}\right)$ and $R\left(K_{D P}\right)$ QPEs have higher values of NRMSE than the S-band when only the systematic bias is corrected. These results can be expected because of less attenuation and the WRE at longer wavelength radars. The values of NRMSE decrease dramatically at $C$ band after the ensuing attenuation correction (brown areas), and the improvements are more pronounced than at $\mathrm{S}$ band. The results indicate that applying a proper attenuation correction can significantly mitigate the impacts of the attenuation effect on the C-band QPEs. The C-and S-band QPEs have a comparable performance after the systemic bias and attenuation corrections.

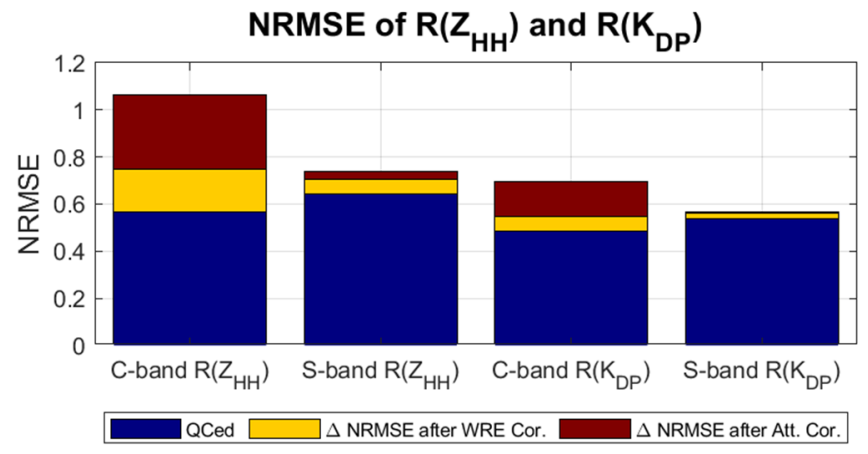

Figure 6. The NRMSEs of the C-band (refer to NCU C-POL) and S-band (refer to RCWF hereafter) QPEs at different levels of $Z_{\mathrm{HH}}$ corrections. The height of each bar indicates the NRMSE after systematic-bias correction only. The brown color represents the reductions of NRMSE after the ensuing attenuation correction, and the yellow marks the reductions after the correction of the wet radome effect (WRE). The blue color is the final NRMSE when all QC procedures, including the systematic-bias, attenuation and wet-radome corrections, are completed.

Removing the WRE further reduces QPE errors (yellow areas). The most pronounced reduction of NRMSE can be found in the C-band $R\left(Z_{H H}\right)$ and $R\left(K_{D P}\right)$ QPEs. The C-band radar is more vulnerable to the weakening of the backscattering power due to rain over the radome. The C-band QPEs show slightly better results compared to S-band after the complete data QC procedures. The $\mathrm{Z}_{\mathrm{HH}}$ correction here is also beneficial to the $\mathrm{R}\left(\mathrm{K}_{\mathrm{DP}}\right)$ algorithms since $Z_{\mathrm{HH}}$ used in light rain is corrected, and more accurate ranges of $Z_{\mathrm{HH}}$ are identified for the decision-tree criterion.

\subsection{C- and S-Band Seasonal and All-Season Coefficients in QPE Algorithms}

The dual-pol QPEs using seasonal and all-seasonal coefficients, respectively, in real case are first examined by comparing their NBIAS (Figure 7 upper panel). The QPEs using seasonal coefficients are consistently less biased than the ones using all-season coefficients. In terms of NRMSE (lower panel), C-band QPEs of seasonal coefficients show lower errors than all-seasonal coefficients, except for the $\mathrm{R}\left(\mathrm{Z}_{\mathrm{HH}}, \mathrm{Z}_{\mathrm{DR}}\right)$ algorithm. For the S-band QPEs, the seasonal $Z_{\mathrm{DR}}$-based algorithms have slightly higher NRMSE values compared to the all-season. It is noticed that both $\mathrm{C}$ - and $\mathrm{S}$-band $\mathrm{R}\left(\mathrm{Z}_{\mathrm{HH}}, \mathrm{Z}_{\mathrm{DR}}\right)$ algorithms using the seasonal coefficients perform much worse. The biased $Z_{\mathrm{DR}}$ measurement due to the uncorrected WRE (visually examined, not shown in the paper) is postulated as the main reason. 


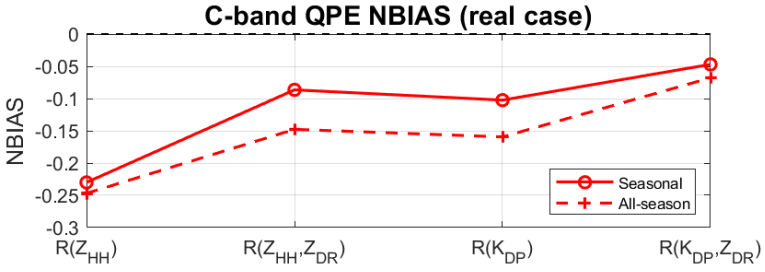

(a)

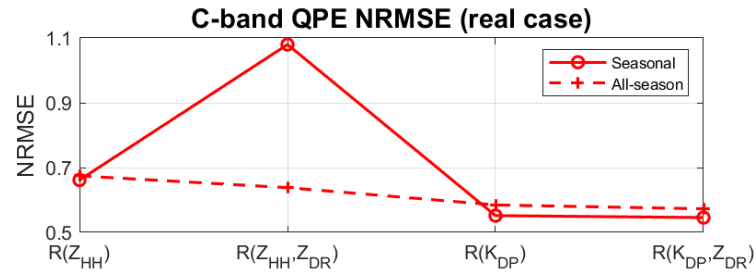

(c)

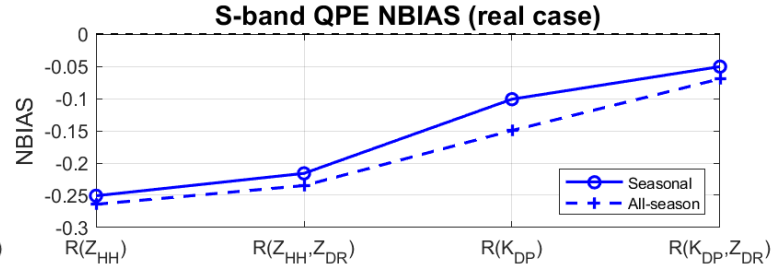

(b)

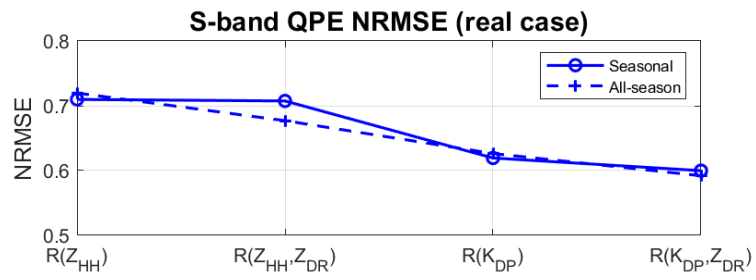

(d)

Figure 7. Same as Figure 4 but from real cases. Eighteen heavy precipitation events observed by NCU C-POL and RCWF are evaluated via rain gauge measurements.

However, the $\mathrm{R}\left(\mathrm{K}_{\mathrm{DP}}, \mathrm{Z}_{\mathrm{DR}}\right)$ algorithms are less affected by $\mathrm{Z}_{\mathrm{DR}}$ than $\mathrm{R}\left(\mathrm{Z}_{\mathrm{HH}}, \mathrm{Z}_{\mathrm{DR}}\right)$. It can be explained by the more negative (more weighted) seasonal exponents of $Z_{\mathrm{DR}}$ in the $\mathrm{R}\left(\mathrm{Z}_{\mathrm{HH}}, \mathrm{Z}_{\mathrm{DR}}\right)$ relations, and the less negative (less weighted) seasonal exponents of $Z_{\mathrm{DR}}$ in $\mathrm{R}\left(\mathrm{K}_{\mathrm{DP}}, \mathrm{Z}_{\mathrm{DR}}\right)$. The sophisticated seasonal $\mathrm{R}\left(\mathrm{Z}_{\mathrm{HH}}, \mathrm{Z}_{\mathrm{DR}}\right)$ algorithms are sensitive to the $\mathrm{Z}_{\mathrm{DR}}$ bias in the real case. The $\mathrm{R}\left(\mathrm{Z}_{\mathrm{HH}}, \mathrm{Z}_{\mathrm{DR}}\right)$ algorithms using seasonal coefficients at S-band shows less deterioration due to the relative insensitivity of $Z_{\mathrm{DR}}$ to the WRE. Overall, $R\left(K_{\mathrm{DP}}\right)$ shows the most improvements after using seasonal coefficients, consistent with the result from the theoretical verification in Section 3.2.

\subsection{C-and S-Band Discrete QPE Comparison (D-QPE)}

The C- and S-band D-QPEs are first compared individually at different rainfall intensities to identify the best algorithm. The NRMSE (or NBIAS) as a function of rainfall intensities are derived by gradually increasing rainfall intensity thresholds in Equations (12) and (13); namely, only the data of $R_{t}>$ rainfall intensity threshold are included for the calculation. In Figure 8 , the $\mathrm{R}\left(\mathrm{K}_{\mathrm{DP}}, \mathrm{Z}_{\mathrm{DR}}\right)$ algorithm shows the lowest NRMSE value over other algorithms consistently at different rainfall intensities at both $\mathrm{C}$ - and S-band radars. The $\mathrm{K}_{\mathrm{DP}}$-based algorithms mostly outperform $\mathrm{Z}_{\mathrm{HH}}$-based algorithms. The $\mathrm{R}\left(\mathrm{Z}_{\mathrm{HH}}, \mathrm{Z}_{\mathrm{DR}}\right)$ algorithm performs worst at $C$-band due to its higher sensitivity of $Z_{D R}$ to the WRE, and $\mathrm{R}\left(\mathrm{Z}_{\mathrm{HH}}\right)$ has the highest values of NRMSE at S-band.

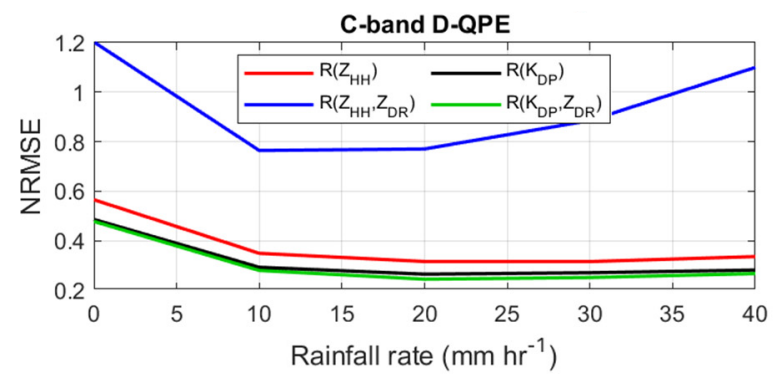

(a)

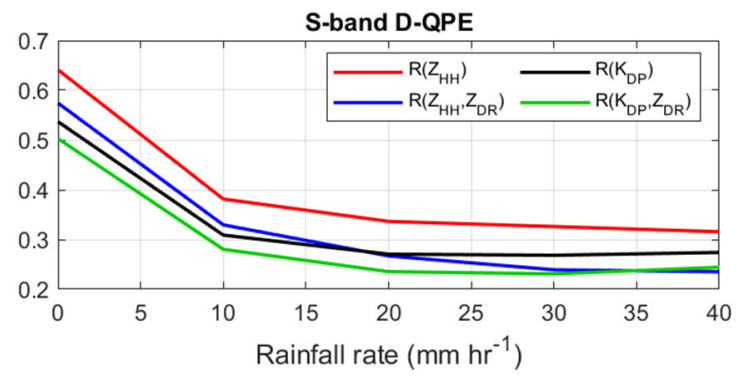

(b)

Figure 8. The NRMSE of D-QPEs as a function of rainfall rates for (a) C-band and (b) S-band D-QPEs.

Subsequently, various D-QPEs from two radars are compared in Figure 9. Except for the $\mathrm{R}\left(\mathrm{Z}_{\mathrm{HH}}, \mathrm{Z}_{\mathrm{DR}}\right)$ algorithm, the C-band D-QPEs are slightly better than S-band D-QPEs, which show smaller errors in heavy rain. Better results from the $C$-band radar can be 
concluded for two reasons. First, the C-band radar is located at a relatively lower altitude and provides radar measurements closer to the surface. Second, the $\mathrm{K}_{\mathrm{DP}}$ measurement is more sensitive to rainfall rate at $C$ band. Beware that the $C$-band QPEs are obtained with a longer radar scan period, otherwise the advantages of the C-band radar would be more noticeable. As the comparable QPEs from S- and C-band radar have been obtained after the complete QC procedures and seasonal coefficients are applied, the integration method is investigated in the next section.

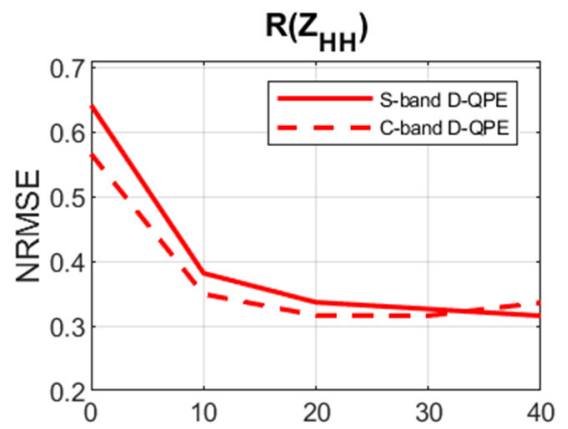

(a)

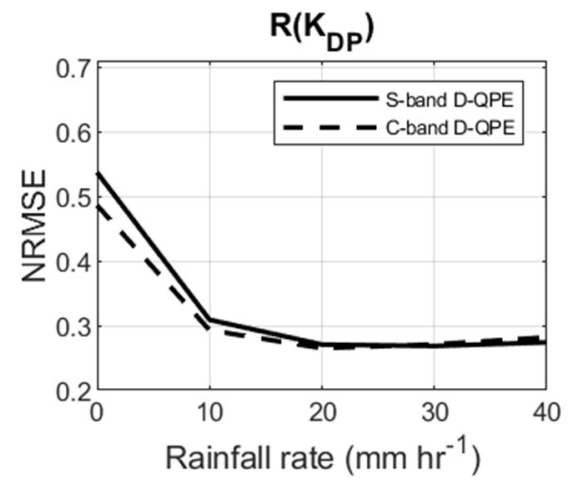

(c)

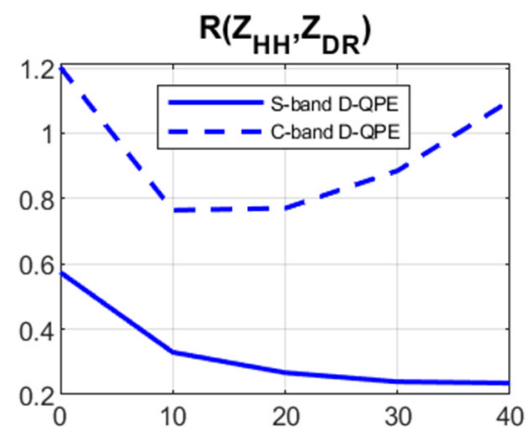

(b)

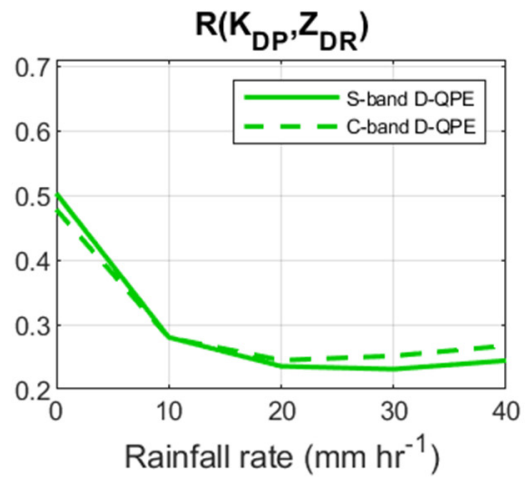

(d)

Figure 9. The NRMSE (as a function of rainfall rates) of C-/S-band D-QPEs from the $(a) R\left(Z_{H H}\right)$, (b) $\mathrm{R}\left(\mathrm{Z}_{\mathrm{HH}}, \mathrm{Z}_{\mathrm{DR}}\right)(\mathbf{c}) \mathrm{R}\left(\mathrm{K}_{\mathrm{DP}}\right)$, and (d) $\mathrm{R}\left(\mathrm{K}_{\mathrm{DP}}, \mathrm{Z}_{\mathrm{DR}}\right)$ algorithm.

\subsection{Discretely Combined C- and S-Band QPEs (DC-QPE)}

The results of DC-QPEs (Figure 10 black lines) show that both $\mathrm{R}\left(\mathrm{K}_{\mathrm{DP}}\right)$ and $\mathrm{R}\left(\mathrm{K}_{\mathrm{DP}}, \mathrm{Z}_{\mathrm{DR}}\right)$, which are the best D-QPEs and thus chosen for further examination, have pronounced improvements. The DC-QPEs outperform both S- and C-band D-QPEs, especially in $\mathrm{R}\left(\mathrm{K}_{\mathrm{DP}}\right.$, $Z_{\mathrm{DR}}$ ), with lower values of NRMSE in all rainfall intensities. The reductions of NRMSE from D-QPEs to DC-QPEs are about $1.5-7.0 \%$ in $\mathrm{R}\left(\mathrm{K}_{\mathrm{DP}}\right)$ and about $3.5-8.5 \%$ in $\mathrm{R}\left(\mathrm{K}_{\mathrm{DP}}, \mathrm{Z}_{\mathrm{DR}}\right)$. The encouraging improvements confirm the fact that radar scanning strategy (i.e., temporal resolution) does play a crucial role in radar-based QPE. Integrating asynchronous D-QPE products can reduce the inaccuracy dramatically by increasing the radar sample number. 


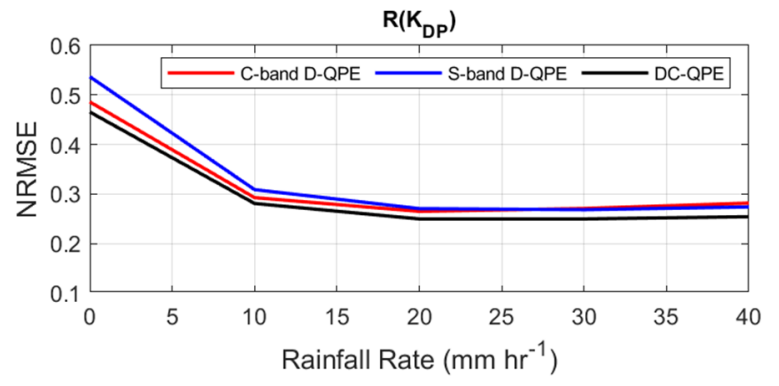

(a)

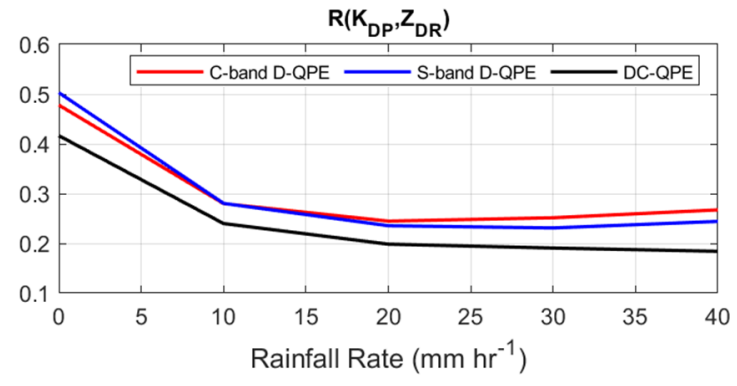

(b)

Figure 10. The NRMSEs of the C-band D-QPE, S-band D-QPE and DC-QPE from the (a) $R\left(K_{D P}\right)$ and $(\mathbf{b}) R\left(K_{D P}, Z_{D R}\right)$ algorithm.

\subsection{Lagrangian-Evolution Adjustment (LEA) QPE}

Figure 11 demonstrates two C-band QPE maps derived from $R\left(K_{D P}, Z_{D R}\right)$ at 06:54 UTC $\left(R_{T_{i}}\right)$ and 07:04 UTC $\left(R_{T_{i+1}}\right)$ on 19 August in 2014. The temporal resolution $\left(\Delta T_{i}\right)$ in this case is $10 \mathrm{~min}$. The convective core $\left(\mathrm{R}>100 \mathrm{~mm} \mathrm{~h}^{-1}\right)$ and precipitation area $\left(\mathrm{R}>10 \mathrm{~mm} \mathrm{~h}^{-1}\right)$ shifted northward noticeably within $10 \mathrm{~min}$. It also clearly shows the precipitation system not only moved fast but also evolved vastly. The heavy rainfall area had expanded, and its intensity had been enhanced. An example of LEA-QPE of $\Delta t_{j}=5 \mathrm{~min}$ is shown in Figure 11c. The convective core (blue $\oplus$ ) is located between the cores of $R_{T_{i}}$ and $R_{T_{i+1}}$ (white and black $\oplus$ ). The movement and evolution of the precipitation structure are also noticeable. There are nine additional LEA-QPEs obtained within these $10 \mathrm{~min}$ using the LEA technique.

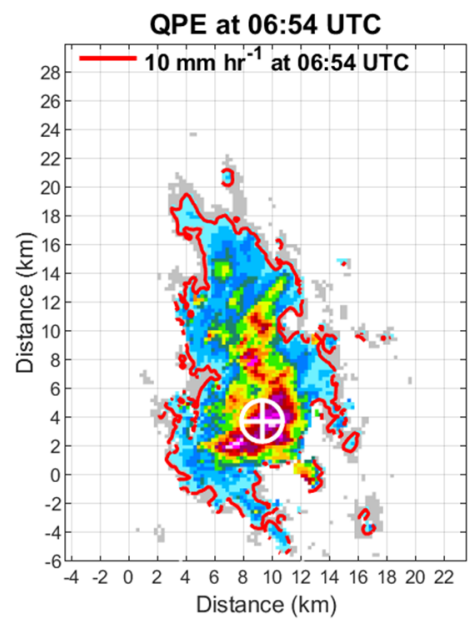

(a)

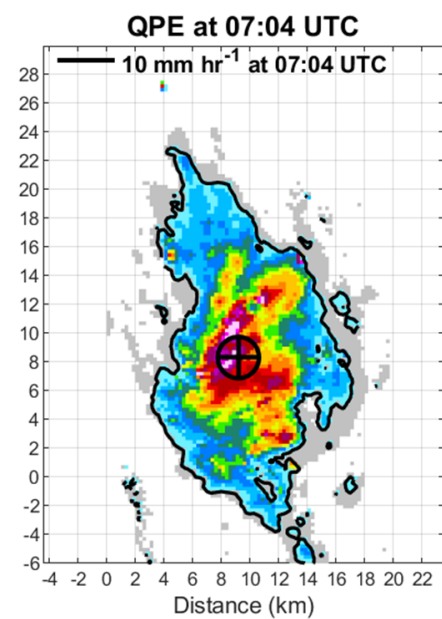

(b)

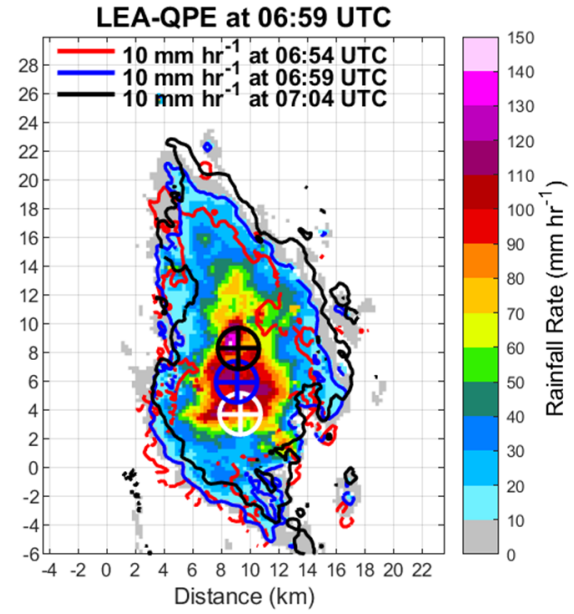

(c)

Figure 11. The C-band QPE maps derived from $\mathrm{R}\left(\mathrm{K}_{\mathrm{DP}}, \mathrm{Z}_{\mathrm{DR}}\right)$ at (a) 06:54 UTC $\left(R_{T_{i}}\right)$ and (b) 07:04 UTC ( $\left.R_{T_{i+1}}\right)$ on 19 August in 2014, and LEA-QPE at (c) 06:59 UTC as $\Delta t_{j}=5 \mathrm{~min}$. The solid contour lines represent the precipitation area $\left(\mathrm{R}>10 \mathrm{~mm} \mathrm{~h}^{-1}\right)$ and $\oplus$ marks indicate the convective core where $\mathrm{R}>100 \mathrm{~mm} \mathrm{~h}^{-1}$.

The C-band radar, which has larger values of $\Delta T$ than the S-band, shows $1-4 \%$ reductions of NRMSE after the LEA algorithm is applied (Figure 12). On the other hand, S-band LEA-QPEs have little improvement with the NRMSE values remaining similar to D-QPEs. Moreover, the C-band LEA-QPEs have consistently lower values of NRMSE than the S-band LEA-QPEs. These results indicate that the LEA algorithm has more positive feedback in the case of large $\Delta T$. The most improvements are found in rainfall rates above $40 \mathrm{~mm} \mathrm{~h}^{-1}$ in $\mathrm{R}\left(\mathrm{K}_{\mathrm{DP}}, \mathrm{Z}_{\mathrm{DR}}\right)$. It is postulated that the evolutions of the precipitation systems 
can be mainly revealed by the RSD variations. Hence, the LEA algorithm can further improve $Z_{D R}$-based QPEs by including the RSD evolutions from $Z_{D R}$ measurements.

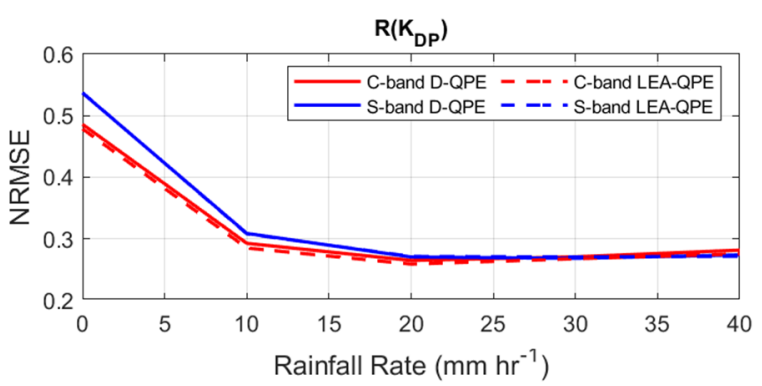

(a)

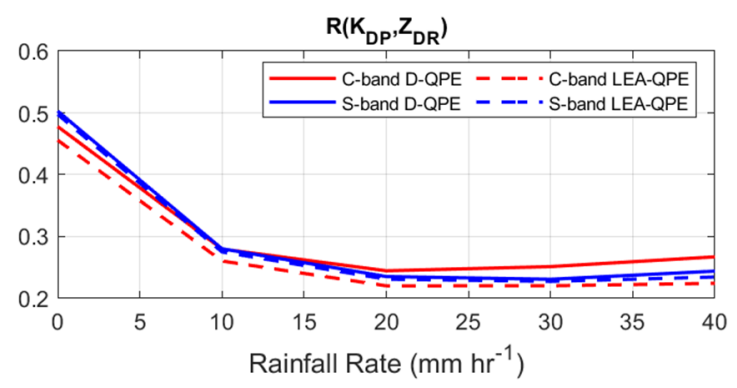

(b)

Figure 12. The NRMSE of C-/S-band D-QPE and LEA-QPE from the (a) $R\left(K_{D P}\right)$ and $(\mathbf{b}) R\left(K_{D P}, Z_{D R}\right)$ algorithm.

As discussed in the previous section, the DC-QPE outperforms the D-QPE by combining the S- and C-band D-QPEs. Applying the LEA technique compensates for the disadvantage of relatively lower temporal resolution at the C-band radar. In Figure 13 (upper panel), the QPEs derived from $\mathrm{R}\left(\mathrm{K}_{\mathrm{DP}}\right)$ show a consistent underestimation of the rainfall rate, and ones from $R\left(K_{D P}, Z_{D R}\right)$ are less biased. When the LEA technique is applied to DC-QPE (LEAC-QPE), the LEAC-QPEs are slightly better than DC-QPEs for $\mathrm{R}>0 \mathrm{~mm} \mathrm{~h}^{-1}$. The difference between LEAC-QPEs and DC-QPEs diminishes as the rainfall intensity increases. NRMSE in the lower panel of Figure 13 shows that the DC-QPEs outperform both the S- and C-band LEA-QPEs with lower NRMSE. LEAC-QPEs show nearly identical NRMSE values to DC-QPEs in both $\mathrm{R}\left(\mathrm{K}_{\mathrm{DP}}\right)$ and $\mathrm{R}\left(\mathrm{K}_{\mathrm{DP}}, \mathrm{Z}_{\mathrm{DR}}\right)$. Overall, the LEAC-QPEs have less biased NBIAS than DC-QPEs and the lowest NRMSE as DC-QPEs.

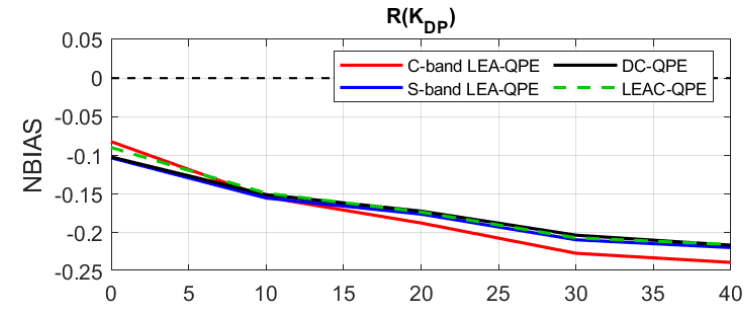

(a)

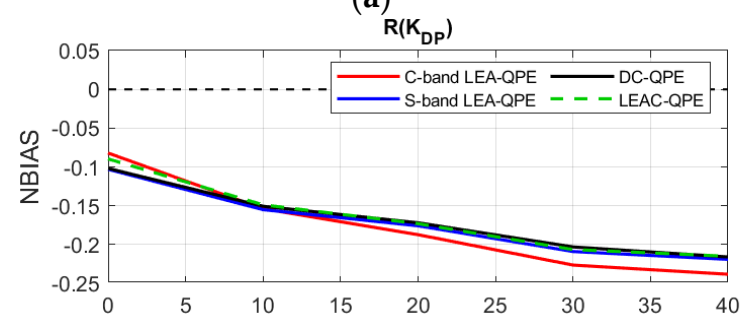

(c)

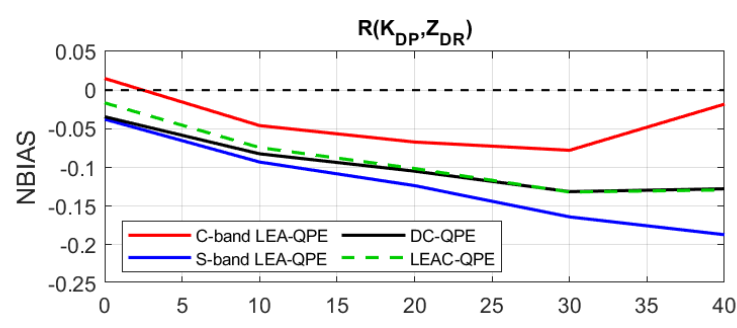

(b)

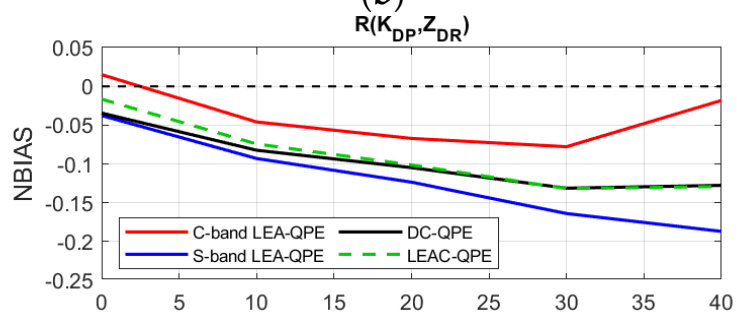

(d)

Figure 13. The NBIAS of C-/S-band LEA-QPE, DC-QPE and LEA DC-QPE (LEAC-QPE) derived from the (a) R(K $\left.K_{D P}\right)$ and (b) $\mathrm{R}\left(\mathrm{K}_{\mathrm{DP}}, \mathrm{Z}_{\mathrm{DR}}\right)$ algorithm. (c) and (d) are the same but showing NRMSE.

\section{Summary}

The dual-pol QPEs of RCWF and NCU C-POL radars have been investigated comprehensively in this study. Three key factors influencing the QPE accuracy, namely, the radar data quality, RSD variability, and the QPE integration method, were examined. Eighteen heavy rain events over northern Taiwan were selected for QPE validation in this work. 
The QC procedures, including the corrections of attenuation, the systematic bias, and the WRE for S- and C-band radars over northern Taiwan, have been documented. Different levels of $Z_{\mathrm{HH}}$ corrections were applied for QPEs for 18 heavy precipitation events. The results show that attenuation and the WRE play crucial roles in QPE, even for S-band radars. The proper QC procedures significantly reduce the QPE uncertainty. The C-band QPE, in the end, performs slightly better than the S-band partially due to the lower altitude of the radar-site. The $\mathrm{R}\left(\mathrm{K}_{\mathrm{DP}}, \mathrm{Z}_{\mathrm{DR}}\right)$ algorithm outperforms other QPEs.

The all-season and seasonal coefficients in four power-law QPE relations derived from eight-year 2DVD disdrometer data were examined to investigate the impact of seasonal RSD variability on QPE. The results indicate that the seasonal coefficients pronouncedly reduce the error by diminishing the $R S D$ variability. The $R\left(Z_{H H}, Z_{D R}\right)$ algorithm has higher values of NRMSE due to the WRE of $Z_{D R}$ measurements.

With the proper QC procedures and seasonal coefficients, the comparable QPEs from S- and C-band radars are thus ready for further composition. Even though these QPEs were from asynchronous S- and C-band radar scanning with different temporal resolutions, two QPE integration methods have been carried out to increase the radar sample number. The D-QPEs from C- and S-band radars were first combined discretely. DC-QPE has improved the QPE accuracy significantly with the reductions of NRMSE about $1.5-7.0 \%$ in $\mathrm{R}\left(\mathrm{K}_{\mathrm{DP}}\right)$ and about $3.5-8.5 \%$ in $\mathrm{R}\left(\mathrm{K}_{\mathrm{DP}}, \mathrm{Z}_{\mathrm{DR}}\right)$ from D-QPE to DC-QPE. However, the D-QPE/DC-QPE may still miss the motion and evolution of the precipitation systems. A newly developed algorithm, namely Lagrangian-evolution adjustment (LEA), is proposed in this study to further improve the QPE performance. The advection of precipitation systems is estimated via a tracking technique, and the evolution is derived via time-weighted linear interpolation. The LEA-QPE has shown a noticeable improvement in $\mathrm{R}\left(\mathrm{K}_{\mathrm{DP}}, \mathrm{Z}_{\mathrm{DR}}\right)$ at the C-band radar, which has larger scanning temporal gaps (up to $10 \mathrm{~min}$ ). NRMSE reduction after the LEA algorithm is about $1-4 \%$. Further combining the DC-QPE and LEA-QPE, namely LEAC-QPE, shows little improvement.

\section{Conclusions}

The individual dual-pol QPE can be significantly improved by two key factors: (1) improving the data quality by applying proper radar data quality procedures, including attenuation, the radar systematic bias and the WRE corrections, and (2) reducing the influence of the RSD variability on dual-pol QPE by applying seasonal coefficients. Consequently, the comparable QPEs from asynchronous S- and C-band radar scans can be composited using more sophisticated integration methods, such as discretely combined QPE and Lagrangian-Evolution Adjustment (LEA) proposed in this study. The synthetic LEA-QPEs by combining S- and C-band dual-pol radars have outperformed conventional QPEs.

Author Contributions: The work presented here was carried out in collaboration with all authors. J.-Y.C. performed data processing, developed algorithms, produced the manuscript; W.-Y.C. helped design the research procedures and analyze the data. P.-L.C. provided the data and participated in discussions on the analyses; J.-Y.C. and W.-Y.C. contributed to the reviewing and revising of the manuscript. All authors have read and agreed to the published version of the manuscript.

Funding: This work was funded by the Ministry of Science and Technology, Taiwan: MOST109-2625M-008-011

Acknowledgments: We thank all of the staff of the Central Weather Bureau of Taiwan for providing valuable radar and rain gauge data used in this paper.

Conflicts of Interest: The authors declare no conflict of interest

\section{References}

1. Marshall, J.S.; Palmer, W.M.K. The distribution of raindrops with size. J. Meteorol. 1948, 5, 165-166. [CrossRef]

2. Radar observation of the atmosphere. L. J. Battan (The University of Chicago Press) 1973. PP X, 324; 125 figures, 21 tables. £7·15. Q. J. R. Meteorol. Soc. 1973, 99, 793. [CrossRef] 
3. Seliga, T.A.; Bringi, V.N. Potential Use of Radar Differential Reflectivity Measurements at Orthogonal Polarizations for Measuring Precipitation. J. Appl. Meteorol. 1976, 15, 69-76. [CrossRef]

4. Seliga, T.A.; Bringi, V.N.; Al-Khatib, H.H. A Preliminary Study of Comparative Measurements of Rainfall Rate Using the Differential Reflectivity Radar Technique and a Raingage Network. J. Appl. Meteorol. 1981, 20, 1362-1368. [CrossRef]

5. Gorgucci, E.; Chandrasekar, V.; Scarchilli, G. Radar and Surface Measurement of Rainfall during CaPE: 26 July 1991 Case Study. J. Appl. Meteorol. 1995, 34, 1570-1577. [CrossRef]

6. Gorgucci, E.; Scarchilli, G.; Chandrasekar, V. Specific Differential Phase Estimation in the Presence of Nonuniform Rainfall Medium along the Path. J. Atmos. Ocean. Technol. 1999, 16, 1690-1697. [CrossRef]

7. Ryzhkov, A.V.; Zrnić, D.S. Comparison of Dual-Polarization Radar Estimators of Rain. J. Atmos. Ocean. Technol. 1995, 12, 249-256. [CrossRef]

8. Ryzhkov, A.V.; Giangrande, S.E.; Schuur, T.J. Rainfall Estimation with a Polarimetric Prototype of WSR-88D. J. Appl. Meteorol. 2005, 44, 502-515. [CrossRef]

9. Ryzhkov, A.V.; Schuur, T.J.; Burgess, D.W.; Heinselman, P.L.; Giangrande, S.E.; Zrnic, D.S. The Joint Polarization Experiment: Polarimetric rainfall measurements and hydrometeor classification. Bull. Am. Meteorol. Soc. 2005, 86, 809-824. [CrossRef]

10. Fulton, R.A.; Breidenbach, J.P.; Seo, D.; Miller, D.A.; O'Bannon, T. The WSR-88D rainfall algorithm. Weather Forecast. 1998, 13, 377-395. [CrossRef]

11. Bringi, V.N.; Chandrasekar, V. Polarimetric Doppler Weather Radar: Principles and Application; Cambridge University Press: Cambridge, UK, 2001; 636p.

12. Illingworth, A.J.; Thompson, R.J. The Estimation of Moderate Rain Rates with Operational Polarisation Radar. In Proceedings of the 32th Conference on Radar Meteorology, Albuquerque, NM, USA, 22-29 October 2005.

13. Hogan, R.J. A Variational Scheme for Retrieving Rainfall Rate and Hail Reflectivity Fraction from Polarization Radar. J. Appl. Meteorol. Climatol. 2007, 46, 1544-1564. [CrossRef]

14. Giangrande, S.E.; Ryzhkov, A.V. Estimation of Rainfall Based on the Results of Polarimetric Echo Classification. J. Appl. Meteorol. Climatol. 2008, 47, 2445-2462. [CrossRef]

15. Ventura, J.F.; Kabeche, F.; Fradon, B.; Hogan, R.; Boumahmoud, A.A.; Illingworth, A.; Tabary, P. Extensive evaluation of Polarimetric Quantitative Precipitation Estimations (QPE) in ideal and less ideal conditions. In Proceedings of the 6th European Conference on Radar in Meteorology and Hydrology, Sibiu, Romania, 6-10 September 2010.

16. Cifelli, R.; Chandrasekar, V.; Lim, S.; Kennedy, P.C.; Wang, Y.; Rutledge, S.A. A New Dual-Polarization Radar Rainfall Algorithm: Application in Colorado Precipitation Events. J. Atmos. Ocean. Technol. 2011, 28, 352-364. [CrossRef]

17. Chen, H.; Chandrasekar, V. The quantitative precipitation estimation system for Dallas-Fort Worth (DFW) urban remote sensing network. J. Hydrol. 2015, 531, 259-271. [CrossRef]

18. Kwon, S.; Jung, S.H.; Lee, G. Inter-comparison of radar rainfall rate using Constant Altitude Plan Position Indicator and hybrid surface rainfall maps. J. Hydrol. 2015, 531, 234-247. [CrossRef]

19. Chang, W.; Vivekanandan, J.; Ikeda, K.; Lin, P. Quantitative Precipitation Estimation of the Epic 2013 Colorado Flood Event: Polarization Radar-Based Variational Scheme. J. Appl. Meteorol. Climatol. 2016, 55, 1477-1495. [CrossRef]

20. Ryzhkov, A.V.; Diederich, M.; Zhang, P.; Simmer, C. Potential utilization of specific attenuation for rainfall estimation, mitigation of partial beam blockage, and radar networking. J. Atmos. Ocean. Technol. 2014, 31, 599-619. [CrossRef]

21. Diederich, M.; Ryzhkov, A.; Simmer, C.; Zhang, P.; Trömel, S. Use of specific attenuation for rainfall measurement at X-band radar wavelengths. Part I: Radar calibration and partial beam blockage estimation. J. Hydrometeorol. 2015, 16, 487-502. [CrossRef]

22. Diederich, M.; Ryzhkov, A.; Simmer, C.; Zhang, P.; Trömel, S. Use of specific attenuation for rainfall measurement at X-band radar wavelengths. Part II: Rainfall estimates and comparison with rain gauges. J. Hydrometeorol. 2015, 16, 503-516. [CrossRef]

23. Wang, Y.; Cocks, S.; Tang, L.; Ruzhkov, A.; Zhang, P.; Zhang, J.; Howard, K. A prototype quantitative precipitation estimation algorithm for operational S-Band polarimetric radar utilizing specific attenuation and specific differential phase. Part I: Algorithm description. J. Hydrometeorol. 2019, 20, 985-997. [CrossRef]

24. Zhang, J.; Tang, L.; Cocks, S.; Zhang, P.; Ryzhkov, A.; Howard, K.; Langston, C.; Kaney, B. A Dual-polarization Radar Synthetic QPE for Operations. J. Hydrometeorol. 2020, 21, 2507-2521. [CrossRef]

25. Ruzanski, E.; Chandrasekar, V. Nowcasting Rainfall Fields Derived from Specific Differential Phase. J. Appl. Meteorol. Climatol. 2012, 51, 1950-1959. [CrossRef]

26. Chang, W.; Vivekanandan, J.; Chen Wang, T. Estimation of X-Band Polarimetric Radar Attenuation and Measurement Uncertainty Using a Variational Method. J. Appl. Meteor. Climatol. 2014, 53, 1099-1119. [CrossRef]

27. Lee, G.W. Sources of Errors in Rainfall Measurements by Polarimetric Radar: Variability of Drop Size Distributions, Observational Noise, and Variation of Relationships between R and Polarimetric Parameters. J. Atmos. Ocean. Technol. 2006, 23, 1005-1028. [CrossRef]

28. Melnikov, V.M. Simultaneous Transmission Mode for the Polarimetric WSR-88D; NOAA/NSSL Report. 2004; 84p. Available online: http:/ / www.nssl.noaa.gov/publications/wsr88d_reports/SHV_statistics.pdf (accessed on 1 June 2018).

29. Chang, P.-L.; Zhang, J.; Tang, Y.-S.; Tang, L.; Lin, P.-F.; Langston, C.; Kaney, B.; Chen, C.-R.; Howard, K. An Operational Multi-Radar Multi-Sensor QPE System in Taiwan. Bull. Am. Meteorol. Soc. 2020. [CrossRef]

30. Wolff, D.B.; Petersen, W.A.; Tokay, A.; Marks, D.A.; Pippitt, J.L. Assessing Dual-Polarization Radar Estimates of Extreme Rainfall during Hurricane Harvey. J. Atmos. Ocean. Technol. 2019, 36, 2501-2520. [CrossRef] 
31. Chang, W.-Y.; Wang, T.-C.-C.; Lin, P.-L. Characteristics of the raindrop size distribution and drop shape relation in typhoon systems in the western Pacific from the 2D video disdrometer and NCU C-band polarimetric radar. J. Atmos. Ocean. Technol. 2009, 26, 1973-1993. [CrossRef]

32. Lee, M.-T.; Lin, P.-L.; Chang, W.-Y.; Seela, B.K.; Janapati, J. Microphysical characteristics and types of precipitation for different seasons over north Taiwan. J. Meteorol. Soc. Jpn. 2019, 97, 841-865. [CrossRef]

33. Chang, P.-L.; Lin, P.-F.; Jou, J.-D.B.; Zhang, J. An application of reflectivity climatology in constructing radar hybrid scans over complex terrain. J. Atmos. Ocean. Technol. 2009, 26, 1315-1327. [CrossRef]

34. O'Bannon, T. Using a 'terrain-based' hybrid scan to improve WSR-88D precipitation estimates. In Proceedings of the 28th Conference on Radar Meteorology, Austin, TX, USA, 7-12 September 1997; American Meteorology Society: Boston, MA, USA, 1997; pp. 506-507.

35. Maddox, R.A.; Zhang, J.; Gourley, J.J.; Howard, K.W. Weather radar coverage over the contiguous United States. Weather Forecast. 2002, 17, 927-934. [CrossRef]

36. Vivekanandan, J.; Zhang, G.; Ellis, S.M.; Rajopadhyaya, D.; Avery, S.K. Radar reflectivity calibration using differential propagation phase measurement. Radio Sci. 2003, 38, 14-1-14-14. [CrossRef]

37. Gorgucci, E.; Bechini, R.; Baldini, L.; Cremonini, R.; Chandrasekar, V. The Influence of Antenna Radome on Weather Radar Calibration and Its Real-Time Assessment. J. Atmos. Ocean. Technol. 2013, 30, 676-689. [CrossRef]

38. Frasier, S.J.; Kabeche, F.; Figueras i Ventura, J.; Al-Sakka, H.; Tabary, P.; Beck, J.; Bousquet, O. In-Place Estimation of Wet Radome Attenuation at X Band. J. Atmos. Ocean. Technol. 2013, 30, 917-928. [CrossRef]

39. Salazar-Cerreño, J.L.; Chandrasekar, V.; Trabal, J.M.; Siquera, P.; Medina, R.; Knapp, E.; McLaughlin, D.J. A Drop Size Distribution (DSD)-Based Model for Evaluating the Performance of Wet Radomes for Dual-Polarized Radars. J. Atmos. Ocean. Technol. 2014, 31, 2409-2430. [CrossRef]

40. Mancini, A.; Salazar, J.L.; Lebrón, R.M.; Cheong, B.L. A Novel Instrument for Real-Time Measurement of Attenuation of Weather Radar Radome Including Its Outer Surface. Part I: The Concept. J. Atmos. Ocean. Technol. 2018, 35, 953-973. [CrossRef]

41. Mancini, A.; Salazar, J.L.; Lebrón, R.M.; Cheong, B.L. A Novel Instrument for Real-Time Measurement of Attenuation of Weather Radar Radome Including Its Outer Surface. Part II: Applications. J. Atmos. Ocean. Technol. 2018, 35, 975-991. [CrossRef]

42. Schönhuber, M.; Urban, H.E.; Poiares Baptista, P.P.V.; Randeu, W.L.; Riedler, W. Weather radar versus 2D-video-disdrometer data. In Weather Radar Technology for Water Resources Management; Bragg, B., Jr., Massambani, O., Eds.; UNESCO Press: Paris, France, 1997; pp. 159-171.

43. Kruger, A.; Krajewski, W.F. Two-dimensional video disdrometer: A description. J. Atmos. Ocean. Technol. 2002, $19,602-617$. [CrossRef]

44. Thurai, M.; Bringi, V.N. Drop axis ratios from 2D video disdrometer. J. Atmos. Ocean. Technol. 2005, 22, 966-978. [CrossRef]

45. Smith, P.L.; Kliche, D.V. The Bias in moment estimators for parameters of drop size distribution functions: Sampling from exponential distributions. J. Appl. Meteorol. 2005, 44, 1195-1205. [CrossRef]

46. Chen, C.S.; Chen, Y.L. The rainfall characteristics of Taiwan. Mon. Weather Rev. 2003, 131, 1323-1341. [CrossRef]

47. Barber, P.; Yeh, C. Scattering of electromagnetic waves by arbitrarily shaped dielectric bodies. Appl. Opt. 1975, 14, $2864-2872$. [CrossRef] [PubMed]

48. Brandes, E.A.; Zhang, G.; Vivekanandan, J. Experiments in rainfall estimation with a polarimetric radar in a subtropical environment. J. Appl. Meteorol. 2002, 41, 674-685. [CrossRef]

49. Rodgers, C.D. Inverse Methods for Atmospheric Soundings: Theory and Practice; World Scientific Co. Pte. Ltd.: Singapore, 2000; 256p. [CrossRef]

50. Hubbert, J.; Chandrasekar, V.; Bringi, V.N.; Meischner, P. Processing and interpretation of coherent dual-polarized radar measurements. J. Atmos. Ocean. Technol. 1993, 10, 155-164. [CrossRef]

51. Hubbert, J.; Bringi, V.N. An iterative filtering technique for the analysis of copolar differential phase and dual- frequency radar measurements. J. Atmos. Ocean. Technol. 1995, 12, 643-648. [CrossRef]

52. Wang, Y.; Chandrasekar, V. Algorithm for estimation of the specific differential phase. J. Atmos. Ocean. Technol. 2009, 26, 2565-2578. [CrossRef]

53. Giangrande, S.E.; McGraw, R.; Lei, L. An application of linear programming to polarimetric radar differential phase processing. J. Atmos. Ocean. Technol. 2013, 30, 1716-1729. [CrossRef]

54. Cifelli, R.; Petersen, W.A.; Carey, L.D.; Rutledge, S.A.; da Silva Dias, M.A.F. Radar observations of the kinematic, microphysical, and precipitation characteristics of two MCSs in TRMM LBA. J. Geophys. Res. Atmos. 2002, 107, 8077. [CrossRef]

55. Rinehart, R.E.; Garvey, E.T. Three-dimensional storm motion detection by conventional weather radar. Nature 1978, 273, 287-289. [CrossRef] 